\title{
An overview of malaria transmission from the perspective of Amazon Anopheles vectors
}

\author{
Paulo FP Pimenta ${ }^{1,2} /{ }^{+}$, Alessandra S Orfano', Ana C Bahia ${ }^{3}$, Ana PM Duarte', \\ Claudia M Ríos-Velásquez ${ }^{4}$, Fabrício F Melo', Felipe AC Pessoa ${ }^{4}$, Giselle A Oliveira ${ }^{1}$, \\ Keillen MM Campos' ${ }^{2}$, Luis Martínez Villegas ${ }^{1}$, Nilton Barnabé Rodrigues ${ }^{1}$, Rafael Nacif-Pimenta', \\ Rejane C Simões ${ }^{5}$, Wuelton M Monteiro², Rogerio Amino ${ }^{6}$, Yara M Traub-Cseko ${ }^{3}$, José BP Lima ${ }^{2,3}$, \\ Maria GV Barbosa ${ }^{2}$, Marcus VG Lacerda ${ }^{2,4}$, Wanderli P Tadei ${ }^{5}$, Nágila FC Secundino ${ }^{1}$
}

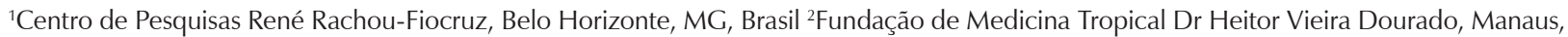
AM, Brasil Instituto Oswaldo Cruz-Fiocruz, Rio de Janeiro, RJ, Brasil ${ }^{4}$ Instituto Leônidas e Maria Deane-Fiocruz, Manaus, AM, Brasil ${ }^{5}$ Instituto Nacional de Pesquisas da Amazônia, Manaus, AM, Brasil ${ }^{\circ}$ Unité de Biologie et Génétique du Paludisme, Institut Pasteur, Paris, France

In the Americas, areas with a high risk of malaria transmission are mainly located in the Amazon Forest, which extends across nine countries. One keystone step to understanding the Plasmodium life cycle in Anopheles species from the Amazon Region is to obtain experimentally infected mosquito vectors. Several attempts to colonise Anopheles species have been conducted, but with only short-lived success or no success at all. In this review, we review the literature on malaria transmission from the perspective of its Amazon vectors. Currently, it is possible to develop experimental Plasmodium vivax infection of the colonised and field-captured vectors in laboratories located close to Amazonian endemic areas. We are also reviewing studies related to the immune response to P. vivax infection of Anopheles aquasalis, a coastal mosquito species. Finally, we discuss the importance of the modulation of Plasmodium infection by the vector microbiota and also consider the anopheline genomes. The establishment of experimental mosquito infections with Plasmodium falciparum, Plasmodium yoelii and Plasmodium berghei parasites that could provide interesting models for studying malaria in the Amazonian scenario is important. Understanding the molecular mechanisms involved in the development of the parasites in New World vectors is crucial in order to better determine the interaction process and vectorial competence.

Key words: Anopheles - Plasmodium - transmission - Amazon vectors

Malaria is an infectious disease that has a major impact on global public health and the economy, with an estimated 3.4 billion people at risk. Currently, malaria threatens almost one third of the world's population in 104 tropical countries and territories where it is considered an endemic disease. The World Health Organization (WHO) estimates that 207 million cases of malaria occurred globally in 2012 and led to 627,000 deaths. Africa, South-East Asia and the Eastern Mediterranean were the regions with the highest numbers of reported cases and deaths reported, mainly in children under five years of age (WHO 2013).

In the Americas, 22 countries are affected by malaria, with approximately 1.1 million cases and 1,100 deaths registered in 2010. In this continent, $30 \%$ of the population is considered to be at risk and $8 \%$ are classified as being at

doi: $10.1590 / 0074-02760140266$

Financial support: Bill \& Melinda Gates Foundation (TransEpi Study), FIOCRUZ, PAPES, CNPq, CAPES, FAPEMIG, FAPERJ, FAPEAM NBR is a CAPES fellow (BEX 11603/13-5).

+ Corresponding author: pimenta@cpqrr.fiocruz.br

Received 22 July 2014

Accepted 18 December 2014 high risk. Areas with a high transmission risk are mainly located in the Amazonian rainforest, which extends across nine countries including Brazil, Bolivia, Colombia, Ecuador, Peru, Venezuela, Guyana, Suriname and French Guiana. Brazil and Colombia accounted for $68 \%$ of the malaria cases in 2011 (PAHO 2011, WHO 2013).

In Brazil, approximately 241,000 clinical cases and 64 deaths were registered in 2012, most of them (99.88\%) in the Amazon Region where malaria is endemic in nine states, namely, Acre, Amapá (AP), Amazonas (AM), Mato Grosso, Pará (PA), Rondônia, Roraima, Tocantins and Maranhão. PA and AM registered almost $70 \%$ of the cases in 2012; $14.4 \%$ were in urban areas, $25 \%$ in gold mine exploitation areas and the others were in rural settlements and indigenous areas (MS/SVS 2013, SVS 2013).

A gradual reduction in the overall number of cases has been observed over the last five years, but there has also been a significant increase in the number of cases in the Brazilian Amazon Region in 2012. Factors that contributed to the increased transmission of malaria include intensive and disorganised occupancy on the outskirts of cities, deforestation and artificial fishponds (MS/SVS 2013, SVS 2013).

Outside the Amazon Region, there were 914 cases registered in 2012 in different Brazilian states, mainly in São Paulo (SP) (188), Rio de Janeiro (130), Minas Gerais (105), Goiás (82) and Piauí (72) (SVS 2013). Most of these cases were due to migration from the Amazon 
Region or from the African continent, but a few were autochthonous from the endemic Atlantic Forest endemic region where few foci are maintained (Rezende et al. 2009, Duarte et al. 2013, Neves et al. 2013).

Malaria is due to infection by a parasitic protozoa of the Plasmodium genus. Several Plasmodium species infect humans and other animals, including birds, reptiles and rodents. In Brazil, three human Plasmodium parasites are prevalent. Plasmodium vivax is the predominant species $(83.81 \%)$ and is responsible for cases associated with severe clinical complications and death (Alexandre et al. 2010, Costa et al. 2012, Lacerda et al. 2012). The prevalence of Plasmodium falciparum (13.15\%) has declined in the last decade, whilst Plasmodium malariae is the least prevalent species $(0.037 \%)$. However, these numbers may be underestimated because the thick blood smear method that is used for routine malaria diagnosis may lead to misidentification of the species (Cavasini et al. 2000).

\section{Plasmodium cycle in the vector}

Mosquitoes of the Anopheles genus are the vectors of the Plasmodium species, the causative agents of malarial disease. More than 400 species of the Anopheles mosquito have been described and approximately 70 these species are potential vectors of malaria that affect humans (Sinka et al. 2012). In the natural vector, the life cycle starts when the female Anopheles mosquito takes a blood meal from an infected vertebrate host and ingests gametocytic forms of the parasite that are present in the blood (Smith et al. 2014).

One mosquito ingests an average of $10^{3}$ gametocytes in an infected blood meal. Within minutes after the infective blood meal, these gametocytes undergo maturation inside the lumen of the midgut, which generates micro and macrogametocytes that will be fertilised and produce a diploid zygote (Sinden 1999). The mature zygote will differentiate into the mobile form of the parasite known as the ookinete via a process that can take up to 16-24 h, depending on the Plasmodium species (Ghosh et al. 2000, Dinglasan et al. 2009). This process starts with the exflagellation of the gametocytes in the mosquito's midgut after ingestion of the infected blood meal. Exflagellation will lead to the formation of the micro and macrogametocytes and occurs mainly due to differences in temperature and $\mathrm{pH}$ and the production of xanturenic acid by the mosquito (Billker et al. 1997, 1998). The formation of the zygote occurs after fertilisation of the micro and macrogametocytes and will eventually differentiate into an ookinete. This development will only occur if the parasites are able to defeat the action of the digestive enzymes that are secreted by the epithelium and are active throughout the midgut. It is believed that the ookinetes in the outer parts of the blood meal will die first from the actions of these digestive enzymes and the ookinetes that are closer to the interior of the blood meal and consequently farther away from the effects of the enzyme, will have a longer time in which to differentiate and survive the actions of the enzyme (Abraham \& Jacobs-Lorena 2004). The ookinete, which is the mobile form of the parasite, will move and penetrate the peritrophic matrix (PM) and pass through the intestinal epithelium before transforming into an oocyst (Smith et al. 2014).

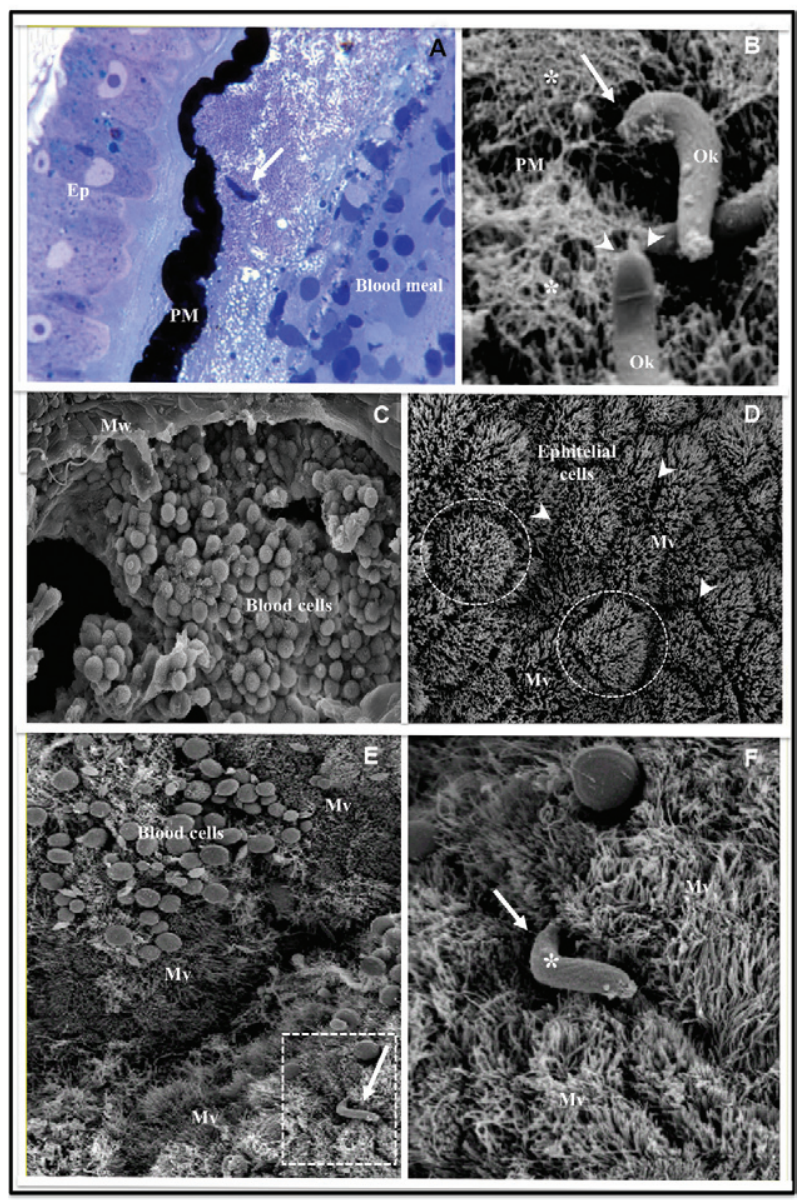

Fig. 1: histology (A) and scanning electron microscopy (SEM) (B-F) of Anopheles aquasalis midguts after a Plasmodium vivax infective blood meal. A: historesin section of a midgut stained with Giemsa. The peritrophic matrix (PM) sturdily stained in black is separating the midgut epithelium (Ep) from the blood meal. Note an ookinete (Ok) (arrow) close to the PM; B: SEM of an opened midgut showing two Oks over the PM. Observe the fibrous aspect (asterisks) of the internal side of the PM. One Ok is crossing the PM throughout the fibre layer (large arrow). Another Ok is showing details of its anterior extremity (arrowheads); C: small magnification of an opened midgut showing the blood meal containing the numerous blood cells. Note a portion of the midgut wall (Mw); D: large magnification of an opened midgut showing details of the epithelial cells. The epithelial cells have polygonal shapes (circles) and their surfaces are covered by microvilli (Mv). Note the clefts (arrowheads) among the epithelial cells; E: small magnification of an opened midgut with blood cells of the blood meal. Note inside the square area one Ok (arrow) penetrating the Ep Mv; F: large magnification of the square area of $\mathrm{E}$ in the Figure showing details of the Ok penetration. Note the Ok (asterisk) extremity inserted in a cleft (asterisk) among the epithelial cell Mv.

The PM is a layer comprised of chitin, proteins and proteoglycans that surround the blood meal that has been ingested (Fig. 1). Physical distension caused by the ingestion of the blood and the blood meal itself are signals for the mosquito's midgut to induce the formation of the PM. This matrix is seen as a physical barrier to many parasites as it prevents their contact with the insect gut (Ghosh et al. 2000). Several studies have suggested that $P$. falciparum and Plasmodium gallinaceum may secrete chitinase additional to that already produced by the in- 
sect which would allow the parasite to accomplish three crucial steps in the infection of the invertebrate host: (i) penetrate through the PM, (ii) escape the deadly action of digestive enzymes and (iii) successfully invade the epithelial cells of the intestine (Huber et al. 1991, Dessens et al. 1999, Vinetz et al. 1999, 2000). The details of the penetration of the PM by the ookinete are seen in Fig. 1A, B. The recently transformed ookinete moves in the direction of the mosquito epithelium (Fig. 1A) and penetrates the $\mathrm{PM}$ by introducing its anterior extremity into the fibrous layer of the internal side of the PM (Fig. 1B).

The penetration of the Plasmodium ookinete into the midgut epithelium is an important step in the infection of mosquitoes and has been thoroughly studied previously (Fig. 1B-F). The epithelial cells have polygonal shapes and their surfaces are covered with microvilli (Fig. 1D). The ookinete penetrates the microvilli clefts that exist among the epithelial cells toward their anterior extremity (Fig. 1E, F) in order to initiate the invasion process.

Different theories have arisen regarding the ookinete's strategies for penetration and invasion of the epithelial cells and escaping detection by the host's immune system. After several years without any conclusive studies on how the ookinete invades the mosquito epithelium, Shahabuddin and Pimenta (1998) used an in vitro system to study the interaction of $P$. gallinaceum with Aedes aegypti. The methodology consisting of the incubation of the parasites with dissected midgut was successfully applied to a study of the Leishmania-vector interaction (Pimenta et al. 1992, 1994). The result suggested the existence of specialised cells in the midgut epithelium of Ae. aegypti that the authors called Ross cells, which would serve as a specific entry point for the ookinete (Shahabuddin \& Pimenta 1998). Subsequently, Han et al. (2000) proposed a time bomb theory in which parasites invade any epithelial cell in the midgut and this process of penetration triggers an immune response, causing this particular cell to begin apoptosis. However, a conclusive report from Barillas-Mury's group at $\mathrm{Na}$ tional Institute of Allergy and Infectious Diseases that was completed with our collaboration (Gupta et al. 2005) indicated that Ae. aegypti and Anopheles stephensi differ in their mechanisms of epithelial repair after Plasmodium ookinete invasion. An. stephensi damaged cells via an actin-mediated budding-off mechanism when invaded by either Plasmodium berghei or P. gallinaceum. In Ae. aegypti, the midgut epithelium is repaired by a unique actin cone zipper mechanism that involves the formation of a cone-shaped actin aggregate at the base of the cell that closes sequentially, expelling the cellular contents into the midgut lumen as it brings together healthy neighbouring cells. This study had important findings: (i) it determined that the apparent target cells used by $P$. gallinaceum to invade the vector epithelium were in fact an in vitro artifact; the Ross cells are believed to represent cells that have lost their integrity and some of their cytoplasmic contents after parasite invasion and (ii) these studies indicated that the epithelial responses of different mosquito vectors to Plasmodium depend on the vector-parasite combinations and are not universal.

After crossing the epithelial layer of the gut, the ookinetes will remain between the intestinal epithelium
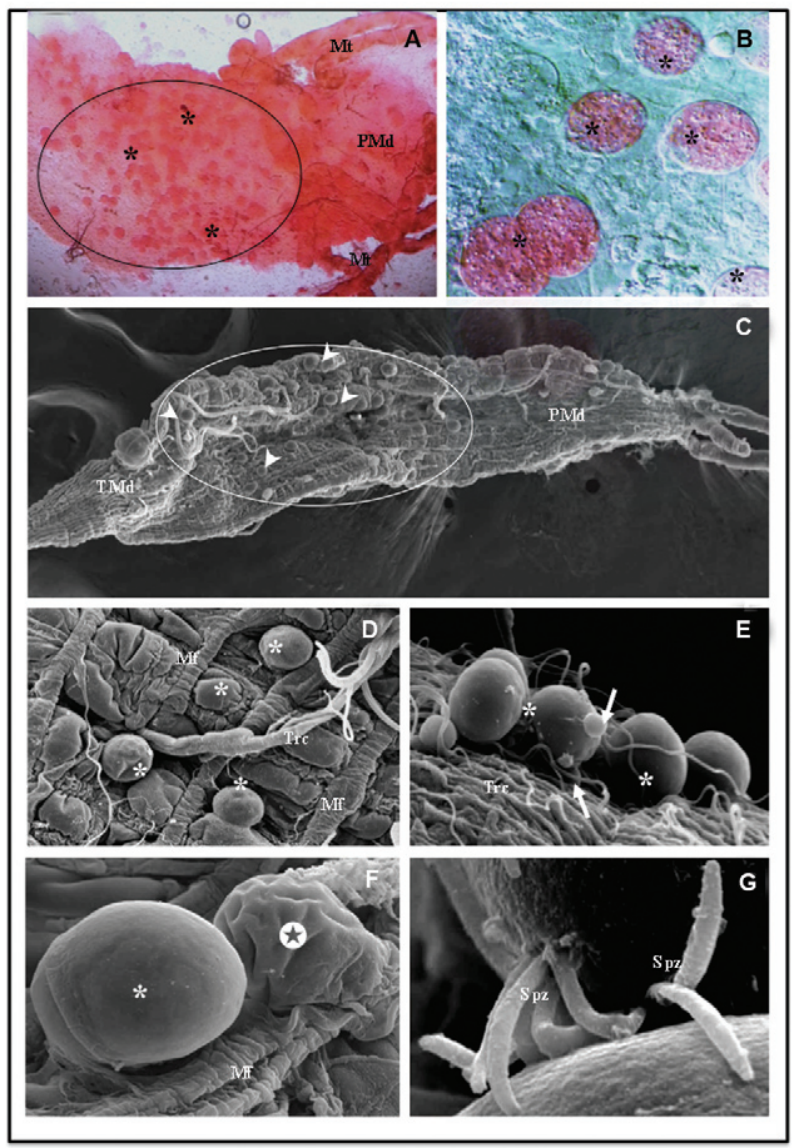

Fig. 2: optical microscopy (OM) and scanning electron microscopy (SEM) of Anopheles aquasalis midguts infected with Plasmodium vivax. A: small magnification of a dissected infected midgut stained with commercial mercurochrome and visualised by an OM. Note in the elliptical area the presence of numerous oocysts (asterisks); B: large magnification image of the A in Figure. Observe the granular aspects of the developing rounded oocysts (asterisks) in the midgut wall; C: SEM small magnification image of a dissected infected midgut. Note inside the elliptical area the presence of several rounded oocysts (arrowheads) protruding from the midgut wall. The oocysts are concentrated in the transition region between the thoracic midgut (TMd) and the posterior midgut (PMd); D: SEM image of oocysts (asterisks) protruding among the microfibres (Mf) that are presenting outside the midgut wall; E: a group of oocysts (asterisks) are seen protruding on the midgut wall. They are surrounding by small tracheoles (Trc). Two haemocytes (arrows) are attached to one oocyst; F: a large magnification view of two oocysts showing one with a smooth surface (asterisk) and another with shrunk surface (black star) possibly due to the liberation of sporozoites (Spz) into the haemocoel; G: large magnification of SEM images of a group of Spz that already escaped from the oocysts and are free in the mosquito haemocoel; Mt: Malpighian tubules.

and the basal lamina, at which point the maturation of the oocyst will occur. A simple method of staining with mercurochrome (Merbromin) solution is useful for the identification of infected midguts. The rounded oocysts can be seen in bright red (Fig. 2A, B). Scanned electron microscope images of the external side of the infected midguts are valuable for showing the morphological aspects of the developing oocysts (Fig. 2C-F). These oocysts appear as protruding structures among the muscle fibres of the midgut wall (Fig. 2D). Some haemo- 


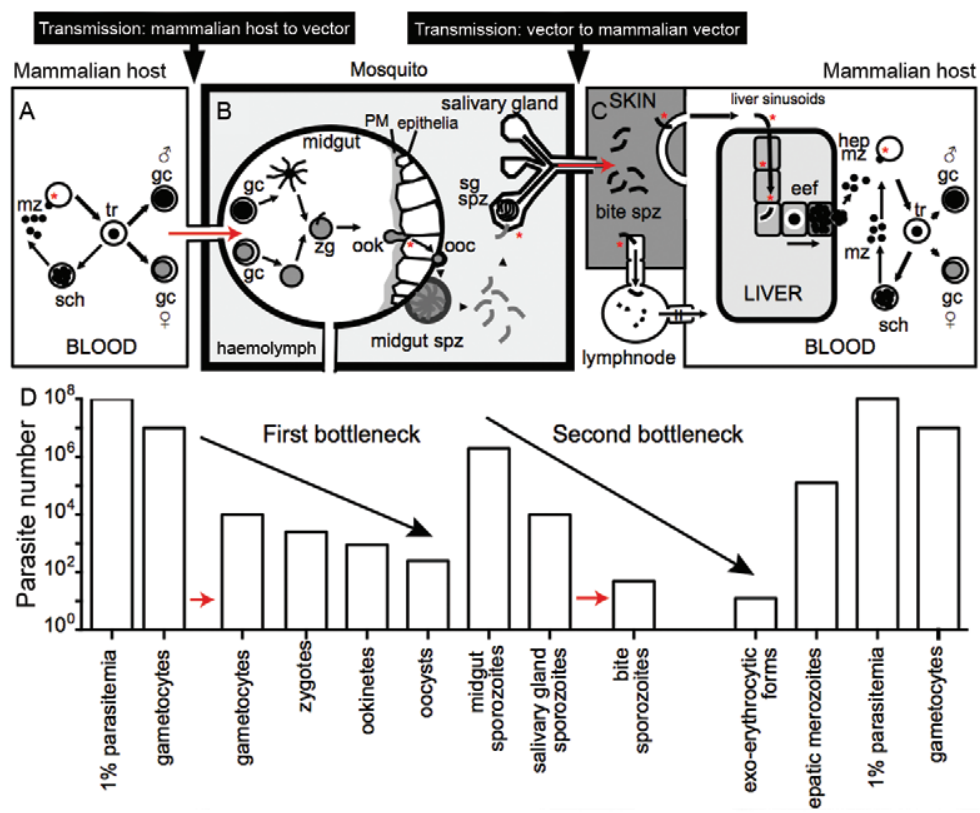

Fig. 3: parasite load inside the vertebrate and invertebrate hosts. Qualitative view of the major steps in the life-cycle of Plasmodium parasites inside the mammalian host (A-C) and the mosquito vector (B). Invasive steps are marked with a red asterisks and parasite transmission by red arrows. A: merozoites (mz) invade red blood cells (RBCs) and transform in trophozoites (tr). After asexual division, tr mature in schizonts (sch), which liberate new $\mathrm{mz}$ in the blood circulation. Some $\mathrm{mz}$ can also differentiate into male or female gametocytes (gc) inside infected RBCs; B: these sexual dimorphic stages are ingested by a mosquito during a blood meal and after activation reproduce sexually generating a zygote (zg). The zg differentiates into the motile ookinete (ook) that crosses the peritrophic matrix (PM) and midgut epithelial cells to develop as an oocyst (ooc) in the laminal basal of the midgut. The ooc then generates midgut sporozoites (spz) that after being released into the haemolymph, invade and are stored in the mosquito salivary glands (sg); C: during the bite the infected mosquito deposits spz (bite spz) in the extravascular parts of the skin. Some spz invade lymph vessels, but are trapped and degraded in the draining lymph nodes. Some spz invade blood vessels and reach the liver sinusoids. After invading the liver parenchyma and traversing host cells, the spz invades and develops as an exoerythrocytic form (eef) in a parasitophorous vacuole inside a hepatocyte. The eef generates hepatic $\mathrm{mz}$ (hep $\mathrm{mz}$ ) that are released inside merosomes in the blood circulation initiating a new cycle of RBC invasion; D: quantitative view of the major steps in the life-cycle of Plasmodium parasites. The bars represent the estimated number of Plasmodium berghei parasites infecting mice and Anopheles stephensi mosquitoes. Data modified from Baton and RanfordCartwright (2005), Medica and Sinnis (2005), Amino et al. (2006) and Sinden et al. (2007). Parameters for estimation: 1e10 RBCs/mouse, $1 \mu \mathrm{L}$ of blood ingested by mosquito, ratio 1 gametocyte: 10 infected RBC, 25\% of bite spz infect hepatocyted, 1 eef generates 10,000 hep mz.

cytes can be seen attached to oocysts (Fig. 2E). It is also possible to observe shrunken oocysts due to the rupture of the oocyst wall (Fig. 2F). Oocyst rupture and the subsequent release of sporozoites occur once the maturation is complete (usually within 10-24 days, depending on the Plasmodium species). This leads to the release of anywhere from hundreds to thousands of sporozoites into the mosquito haemocoel (Hillyer et al. 2007) (Fig. 1G). Before reaching the salivary gland, the sporozoites still need to overcome the other barriers that is produced by the immune system, including: (i) haemocytes (Fig. 2E), which are cells that are responsible for the internal defense system of the mosquito, (ii) antimicrobial peptides and (iii) other humoral factors (Dimopoulos et al. 2001).

In general, the process of invasion of the salivary gland by sporozoites is very inefficient; usually less than $20 \%$ of the total numbers of parasites produced are able to invade the organ (Korochkina et al. 2006, Hillyer et al. 2007). Those sporozoites that survive after overcoming various barriers to reaching the salivary gland are finally able to invade the organ. By means of a specific recognition receptor present in the salivary gland of the vector, these parasites are able to adhere to and penetrate the basal lamina of the gland before penetrating the host plasma membrane of the salivary cells. A number of parasite ligands are necessary for the initial attachment of the sporozoites to the salivary glands, such as some regions of the circumsporozoite protein and thrombospondin-related anonymous protein [see details in Sinden and Matuschewski (2005) and Aly et al. (2009)]. This process of invasion has been well described using the P. gallinaceum/Ae. aegypti model (Pimenta et al. 1994). The penetration process appears to involve the formation of membrane junctions. Once inside the host cells, the sporozoites are seen within vacuoles attached by their anterior end to the vacuolar membrane. Mitochondria surround and are closely associated with the invading sporozoites. After the disruption of the membrane vacuole, the parasites traverse the cytoplasm, attach to and invade the secretory cavity through the apical plasma membrane of the cells. Inside the secretory cavity, the sporozoites are again seen inside the vacuoles. Upon escaping from these vacuoles, the sporozoites are positioned in parallel arrays, forming large bundles attached by multilamellar membrane junctions. Several sporozoites are seen inside and around the secretory duct. Except for the penetration of the chitinous salivary duct, these observations have morphologically characterised 
the entire process of sporozoite passage through the salivary gland (Pimenta et al. 1994). The sporozoites that are now inside the secretory duct of the salivary gland are ready to be injected by the mosquito bite into the skin of a new vertebrate host. An analysis of the amount of parasite that an infected mosquito could inject into the skin of a mouse varied between zero and approximately 1,300 and there appears to be a weak correlation of the number of injected sporozoites with the salivary gland load (Medica \& Sinnis 2005).

Considering the entire Plasmodium life cycle in the vector and in the vertebrate host, it is fascinating to observe the complexity of distinct developmental forms and the parasite load during the course of infection. There is extraordinary adaptation of the Plasmodium parasite to its environment, which is reflected in morphological changes and the parasite load of distinct organs inside the vertebrate host and the mosquito vector (Baton \& Ranford-Cartwright 2005, Medica \& Sinnis 2005, Amino et al. 2006, Ma et al. 2010, Smith et al. 2014). During the stages that the Plasmodium moves from the mammalian host to the vector and vice versa, two "bottlenecks" occur that are characterised by a small number of parasites. Fig. 3 shows an animated model that illustrates qualitative and quantitative views of the major steps of the life cycle of the $P$. berghei parasites infecting mice and An. stephensi mosquitoes. Murine-Plasmodium spp interaction studies are considered to be suitable experimental models to better understand the interaction between malarial parasites and vectors.

\section{The key Amazon Anopheles vectors}

Among the Anopheles mosquito species that inhabit the Amazon, Anopheles darlingi, Anopheles albitarsis s.l. and Anopheles aquasalis are considered the principle mosquito vectors. Specifically, An. darlingi is the main vector in South America and has been associated with the dynamics of malaria transmission in the Amazonian regions of Bolivia, Colombia, French Guiana, Guyana, Peru, Suriname and Venezuela (Zimmerman 1992, Hiwat et al. 2010). An. albitarsis s.l. inhabits regions of Venezuela (Rubio-Palis et al. 1992) and An. aquasalis is found in Trinidad (Chadee \& Kitron 1999), Guyana (Laubach et al. 2001) and Venezuela (Berti et al. 1993).

Other anopheline species can be secondary or occasional malaria vectors because of their population density, anthropophilic behaviour and natural infectivity across their geographical distributions (Deane 1986, Zimmerman 1992, Sinka et al. 2010, 2012). Anopheles nuneztovari s.l. and Anopheles triannulatus s.l. are commonly collected in the Amazon by researchers and they have been observed to be infected with $P$. vivax and $P$. falciparum, but their role as malaria vectors has yet to be elucidated (de Arruda et al. 1986, de Oliveira-Ferreira et al. 1990, Klein et al. 1991b, Tadei \& Dutary 2000, da Silva-Vasconcelos et al. 2002, Póvoa et al. 2003, 2006, dos Santos et al. 2005, Galardo et al. 2007, da Rocha et al. 2008, Santos et al. 2009).

Recently, Foley et al. (2014) developed a study considering the percentage of the area predicted to be suitable for mosquito habitation based on ecological niche mod- els of Amazon vectors. They found that An. albitarsis I, Anopheles janconnae and Anopheles marajoara had the highest percentage of their predicted suitable habitats overlapping the distribution models of $P$. falciparum and $P$. vivax [see details in Foley et al. (2014)]. They also concluded that phylogenetic proximity might be related to malaria vectorial importance within the Albitarsis group. The authors recognised that these findings would encourage additional studies of the transmission potential of these Amazonian Anopheles species.

An. aquasalis is distributed predominantly along the Atlantic Coast because of its tolerance to saltwater environments, including in Venezuela, where it is considered to be the primary coastal malaria vector of $P$. vivax (Galvão et al. 1942, Laubach et al. 2001, Póvoa et al. 2003, da Silva et al. 2006a).

Amazonian Anopheles species such as, Anopheles deaneorum, An. marajoara, Anopheles mattogrossensis, An. nuneztovari, Anopheles oswaldoi, Anopheles rondo$n i$ and An. triannulatus have been considered "naturally infected" with Plasmodium since they were captured with parasites in their blood meal (Galvão et al. 1942, Deane et al. 1948, de Arruda et al. 1986, Klein et al. 1991b, Branquinho et al. 1993, Tadei \& Dutary 2000, Póvoa et al. 2001, 2003, 2006, da Silva-Vasconcelos et al. 2002, da Silva et al. 2006a, Galardo et al. 2007, da Rocha et al. 2008, Santos et al. 2009). However, their role as malaria vectors is not well defined.

Two crucial factors needed to label a mosquito a vector are the demonstration that the species is anthropophilic and identification of the same Plasmodium species or strain in patients from the same geographic region. In the field, the presence of Plasmodium oocysts in the mosquito midgut indicates parasite establishment in a susceptible vector. However, the discovery of only sporozoites in the dissected mosquito salivary gland can confirm that the life cycle is complete and consequently that the Plasmodium parasite can be transmitted by a bite to human hosts. Moreover, recognition of the infection rate (i.e., the percentage of individuals in a mosquito population that carry Plasmodium) is an important parameter for defining vector competence and thus a key indicator in the description of malaria dynamics and transmission biology in a given geographic region. In contrast, the sole presence of an apparent abundance of a species along with parasites in the ingested blood meal is not sufficient to implicate a mosquito as a vector (Smith et al. 2014).

\section{Colonisation of American anophelines}

Considering An. darlingi, An. albitarsis s.l. and An. aquasalis is as main vectors, only the latter species has been colonised for several years under laboratory conditions (Lima et al. 2004). The maintenance of mosquito vectors in a laboratory facilitates studies on their biology and behaviour and experimental studies to characterise details of their susceptibility to Plasmodium species, thus providing a greater understanding of malaria disease dynamics. Mosquito vectors of malaria from Africa and Asia have been well established in colonies and can be maintained in insectaries of several laboratories in different countries. Consequently, Anopheles gambiae, 
the major vector in several African countries, is the most well studied mosquito, including its interaction with human and murine Plasmodium species that are considered causative agents of malaria (Moores 1953). Distinctly, the colonisation of An. darlingi, the major Amazon vector, has proven to be difficult, as has that of other New World anopheline species.

Several attempts to colonise American species of Anopheles under laboratory conditions have been conducted either unsuccessfully or with short-lived success. When describing the rationale for establishing a colony of Anopheles quadrimaculatus, Boyd et al. (1935) highlighted two key starting points: (i) an abundant supply of food for the larvae and (ii) a stable and optimal temperature. Galvão et al. (1944) used Boyd's technique with specifically sized cages $(40 \times 40 \times 47 \mathrm{~cm})$. They loaded approximately two thousand mosquitoes into each cage and the females started to lay eggs after seven days. Reproduction led to An. albitarsis domesticus (An. marajoara) mosquitoes reaching the seventh generation. Egg production in Anopheles tarsimaculatus (An. aquasalis), however, was low and was maintained by only a few dozen couples up to the fifth generation. The authors attributed the colonisation problems to a lack of mating due to the space and type of food offered to the males. To begin a mosquito colony there are numerous factors that need to be controlled for, including the fact that several species do not undergo free copulation under laboratory conditions (Martinez-Palacios \& Davidson 1967). Thus, for the establishment of the colony, the induced copulation approach is often necessary. This method was developed by McDaniel and Horsfall (1957) for the Aedes spp and was later adapted by Baker et al. (1962) for Anopheles.

There are descriptions in the literature of various American Anopheles species that have been maintained in insectaries for short periods of time, including Anopheles punctipennis, Anopheles maculatus, An. aquasalis, An. albitarsis, An. deaneorum and An. marajoara (Baker et al. 1962, Ow-Yang \& Maria 1963, Baker 1964, Arruda et al. 1982, Klein et al. 1990, Horosko III et al. 1997). In the 2000s, the colonisation of Anopheles pseudopunctipennis, which is considered an important vector of human Plasmodium spp along the Andes in several countries, was noted to have occurred by means of free intercourse (Lardeux et al. 2007). The adult mosquitoes were exposed to a blue strobe light for 20 min for several nights, encouraging them to copulate naturally under laboratory conditions. After a few generations, the researchers obtained a stable colony that reproduced by free mating. Corrêa et al. (1970) described some success in colonising and maintaining $A n$. darlingi mosquitoes for about two years. Subsequently, however, Buralli and Bergo (1988) failed to achieve successful results from the same laboratory and using the same methodology. More recently, Moreno et al. (2014) described a method for An. darlingi colonisation that also used the strobe light approach. They reported that An. darlingi mosquitoes obtained after five generations were successfully infected with $P$. vivax by artificial membrane feeding similar to the previous work of RíosVelasquez et al. (2013) with field-captured mosquitoes.
One of the authors of this paper established colonies of two species of Neotropical anophelines 20 years ago. An. albitarsis s.l. was colonised in 1993 by induced copulation. After about two years of colony maintenance with induced copulation, we noticed the successful occurrence of free copulation; we used large cages with a thousand adults and a sex ratio of approximately 1:1 (Horosko III et al. 1997). An. aquasalis was settled in 1995 from the beginning by the free coupling method. In 1998, a second American malaria vector was colonised, Anopheles albimanus, which is one of the main vectors of malaria in Central America and in the south of Mexico (Zerpa et al. 1998). The authors used a simple and efficient maintenance method for mosquito mating and laying eggs.

Today, to the best of our knowledge and according to the specialised literature related to Anopheles species, only two long-term colonised American malaria vectors, An. aquasalis and An. albimanus, are maintained in laboratories and have been used for experimental studies, demonstrating that they are good models for studying the interaction of malaria vectors with Plasmodium species. As examples of these types of studies in An. albimanus, there are reports showing the susceptibility of the vector to P. vivax (Herrera et al. 2011, Solarte et al. 2011) and to the murine P. berghei (Serrano-Pinto et al. 2010, Herrera-Ortiz et al. 2011). For An. aquasalis, there have been studies developed by our group related to their susceptibility to $P$. vivax infection, including those related to gene expression during parasitic infection (Bahia et al. 2010, 2011, 2013, Ríos-Velasquez et al. 2013).

\section{Searching for a model to study the Plasmodium interaction with an American mosquito vector}

An. aquasalis in nature: distribution, habitat and population variability - An. aquasalis lives in sunny habitats with vegetation in fresh brackish water. It is believed that the mosquito prefers clean water such as that in stream pools, mangroves, ponds and ditches (Manguin et al. 1993, Grillet 2000). The demarcation of the An. aquasalis territory to coastal regions and its tolerance to salt water could be evolutionary adaptations that have been selected to avoid competition for food with other Anopheles mosquitoes (particularly during the larval phases), inserting the mosquito into the large and varied marine trophic chain (Sinka et al. 2010). The geographic distribution of An. aquasalis covers the southern coastal region of Central America, the Caribbean Islands and South America, but this species can penetrate eight- 10 miles inland from the coast because it has a flight capacity of up to $8 \mathrm{~km}$. Its presence at the Atlantic Coast has been reported from SP to Nicaragua and at the Pacific Coast from Costa Rica to Ecuador, as well as in the Antilles and Trinidad and Tobago (Faran 1980, Chadee et al. 1992, Zimmerman 1992, Consoli \& Lourenço-de-Oliveira 1994).

An. aquasalis is an important $P$. vivax vector that is present at the Atlantic and Pacific coasts from Central America to southern Brazil. In situations in which the mosquito density increases, females can be the vectors of human malaria, especially in the absence of domestic animals, which are their usual food source. For exam- 
ple, Giglioli (1963) reported the effect of mechanisation on a rice farm in Guyana, which led to the disappearance of buffalo in the region. This resulted in a change in the behaviour of An. aquasalis that had man as its main blood source. Nevertheless, this mosquito species has been associated with several outbreaks of malaria in several countries (Deane 1986, Berti et al. 1993, Laubach et al. 2001, Mouchet et al. 2008). In most of the territory it inhabits, this species is exophilic, zoophilic and crepuscular, but in the drier northeast area it is frequently endophilic and bites human hosts. The females are opportunists, feeding in both intra and peridomiciliary areas of animals and humans. They begin to bite at sunset, reaching maximum activity in the early evening before decreasing later at night (Flores-Mendoza et al. 1996). Usually the mosquitoes rest in their peridomestic habitats before and after the blood meal.

Due to the importance of An. aquasalis as a vector of human malaria, it is necessary to perform studies to evaluate the genetic structure of diverse populations. In general, many Anopheles species are formed by complexes of cryptic species. The taxonomic elucidation of these complexes could reflect on the epidemiology and even on the control of malaria (Rosa-Freitas et al. 1998). To elucidate the dilemma of whether a given species is highly polymorphic or a complex of related species, an integrated approach of performing several studies is necessary. These studies comprise taxonomic investigations applying morphological, behavioural and molecular tools.

In its previous description, An. aquasalis was divided into two varieties: An. tarsimaculatus var. aquacaelestis, presenting the second hind tarsus with less than $1 / 6$ of the length being black and An. tarsimaculatus var. aquasalis, with nearly $1 / 2$ of its length being black (Curry 1932). Based on the morphological characters, many synonymous examples were proposed for this species. In 1941, Komp changed the name of the species known as An. tarsimaculatus var. aquacaelestis to Anopheles (Nyssorhynchus) emilianus by analysing egg characteristics. By studying the morphological characteristics of the eggs, larvae and adults, da Ramos (1942) renamed the same species An. (N.) oswaldoi guarujaensis. While working in Venezuela in 1948, Anduze (1948) found two different tonalities of mosquitoes and changed the name of the so-called An. aquacaelestis and An. aquasalis to var. guarauno and var. delta, respectively. Garcia et al. (1977) were working in Venezuela and studying several morphological characteristics in 1977 when they described An. aquasalis as a new species called Anopheles (Nyssorhynchus) deltaorinoquensis. While still working on Venezuelan mosquito populations in 1997, Maldonado et al. (1997) showed that the egg morphology of An. aquasalis varies within the species. More recently, a systematic study based on the morphological characteristics supported the single species status for An. aquasalis (Sallum et al. 2000). However, as a result of these data using morphological tools, the species complex dilemma has yet to be resolved.

To elucidate the taxonomic relationships among $A n$. aquasalis and An. emilianus in Venezuela, Perez and Conn (1992) conducted a chromosomal banding pattern study on polytene chromosomes of different mosquito populations from endemic and non-endemic areas in that country. They observed that the banding patterns of the populations were identical to the standard chromosome map of An. aquasalis from Brazil. In 1993, Conn et al. analysed populations of An. aquasalis from Venezuela, Trinidad and Brazil using restriction enzyme digestion of mitochondrial DNA (mtDNA). The five enzymes surveyed yielded $12 \mathrm{mtDNA}$ haplotypes. Estimates of mtDNA sequence divergence between all the populations were within the range of interspecific distances calculated for members of the anopheline species complexes. These results suggest a possible interspecific division in An. aquasalis populations north and south of the Amazon River delta (Conn et al. 1993, Linley et al. 1993). In 2002, examining variations in a fragment of the mitochondrial cytochrome oxidase I gene from five An. aquasalis Brazilian populations from PA and AP, Fairley et al. (2002) tested the hypothesis that the freshwater Amazon River acts as a barrier to gene flow in northeastern Brazil. Analytical results suggested that the localities within this region of northeastern Brazil constitute a single large population of An. aquasalis that spans the Amazon River delta.

To test the populations on either side of the Orinoco River (which is another potential freshwater barrier to gene flow for An. aquasalis), intragenomic heterogeneity of the internal transcribed spacer (ITS) 1 and ITS2 arrays were investigated by Fairley et al. (2005) in mosquito populations from two geographic locations each in Brazil and in Venezuela and in a single location in Suriname. No sequences from either ITS had a diagnostic distribution or were informative for distinguishing between these populations, providing additional support for the status of An. aquasalis as a single species. In this same year, the relationship between An. aquasalis and other Amazonian malaria vectors was tested using the rDNA sequence ITS2. The results showed that this marker is compatible with the morphological taxonomic key established for Amazonian mosquitoes and that ITS2 sequence data has proven to be useful in species identification and potentially to solve taxonomic problems (Marrelli et al. 2005). The same results were obtained in Colombia (Cienfuegos et al. 2011). Specifically, there were only five point mutations reported for ITS2 (Fairley et al. 2005). Two interesting questions that remain are how great is the morphological and genetic variability of An. aquasalis in endemic areas and are these factors related to vector competence for malarial parasites.

Experimental Plasmodium infection of mosquito vectors - One keystone step to understanding the Plasmodium life cycle is the development of infectious mosquito vectors. Experimental infection models are used to understand the biology of the interaction between Plasmodium parasites and Anopheles mosquitoes. Most research projects have used laboratory models consisting of the human parasite $P$. falciparum, murine parasites $P$. berghei and Plasmodium yoelii and the avian parasite $P$. gallinaceum interacting with An. gambiae, An. stephensi, An. albimanus and Ae. aegypti mosquitoes. These mosquito species show different susceptibilities to infection 


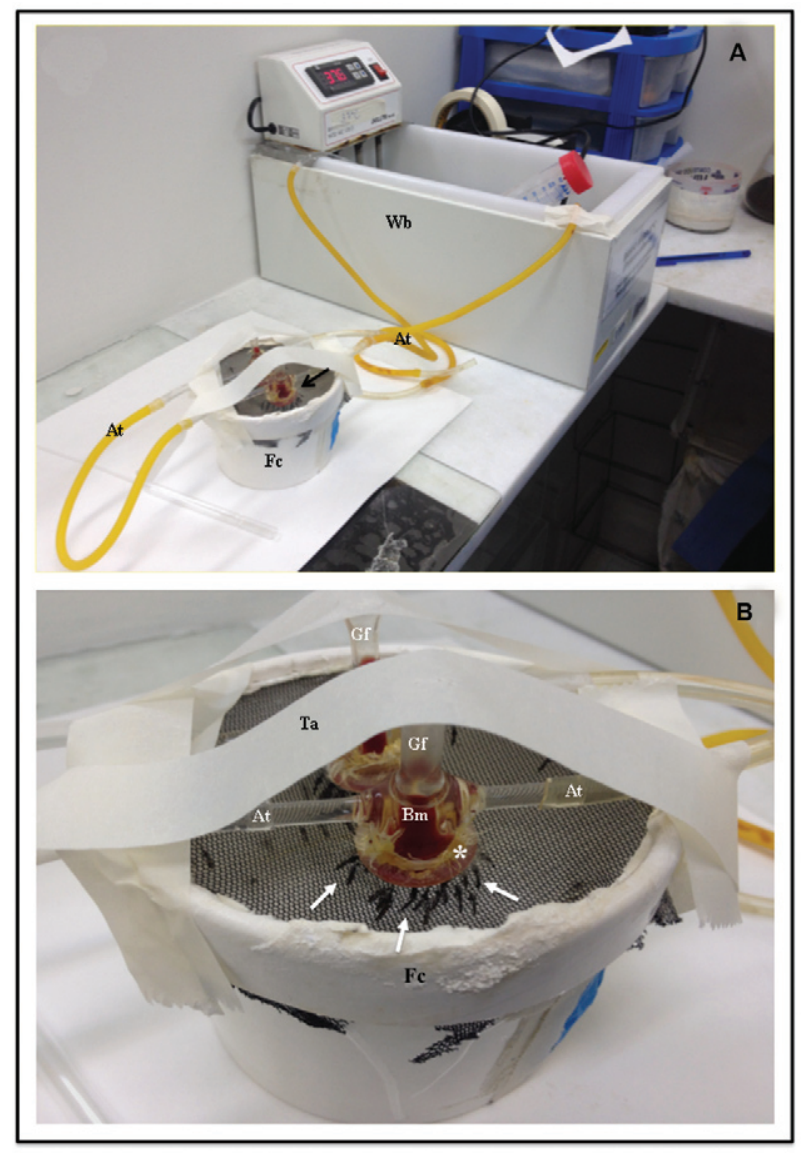

Fig. 4: photographs of the apparatus for developing experimental infection of Anopheles aquasalis. A: a small feeding cage $(\mathrm{Fc})$ for containing the mosquito is seen connected to yellow aquarium tubings (At) that are linked to a water thermal bath (Wb) with $37-39^{\circ} \mathrm{C}$ circulating warm water; B: large magnification image of A in Figure showing details of the Fc. Note the glass feeder (Gf) device placed over a black mesh clothing fabric (asterisk) that is covering the Fc. The Gf is filled with an infective blood meal (Bm), linked to the At and covered by a chicken skin membrane (asterisk). Note several mosquitoes (arrows) in the feeding activity (arrows); Ta: tape for holding the Gf.

by the Plasmodium spp. All of these parasite species are cultured in the laboratory or maintained in experimental animals, making it easy to develop experimental research, but some combinations of parasite-mosquito do not occur in nature and might not resemble the real interactions seen between parasites and their vectors (Boete 2005).

In the past, experimental infection of mosquito vectors was initiated by direct placement of the mosquitoes on the skin of malarial patients to encourage feeding (Klein et al. 1991a, c, da Silva et al. 2006b). Due to ethical issues, these types of studies are currently leaning towards the use of membrane-feeding assays instead in order to minimise the human interaction factor. Several studies have confirmed that offering a blood meal through a membrane-feeding device is as efficient as direct feeding on human skin for the study of Plasmodium infection of mosquito vectors. A comparative study developed by Gouagna et al. (2013) compared the field-based xenodiagnoses and direct membrane feeding
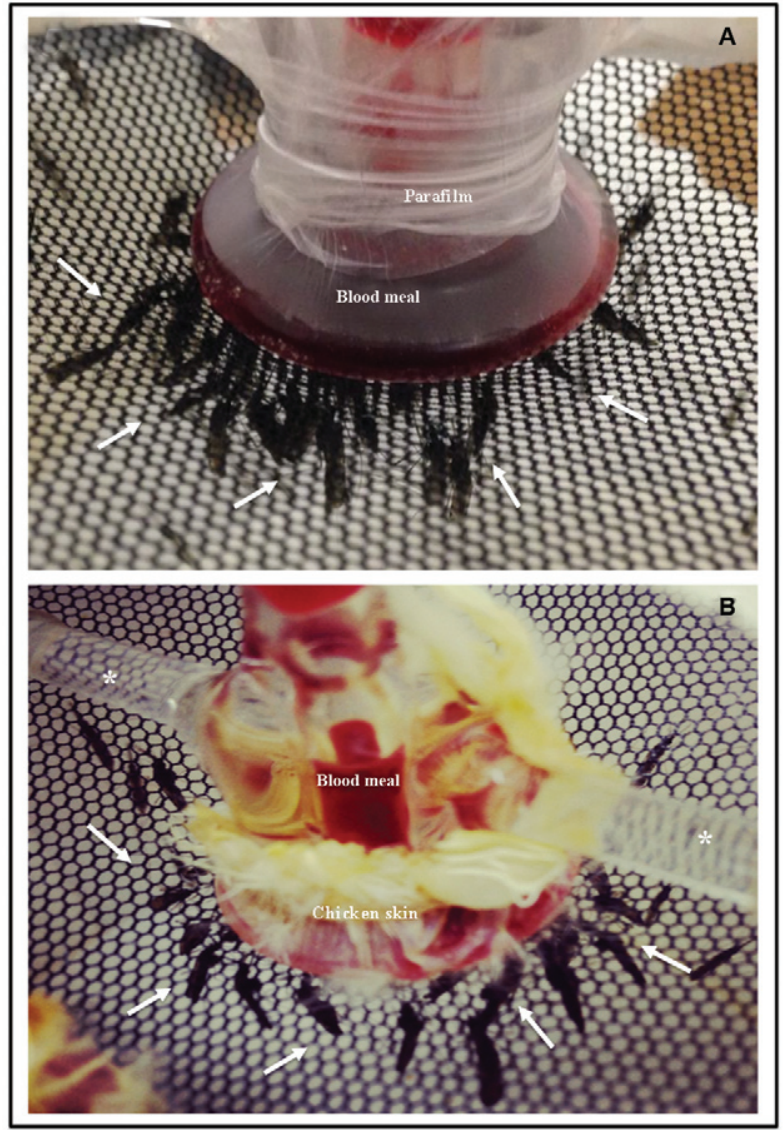

Fig. 5: photographs showing details of the glass feeders for developing experimental infection of Anopheles aquasalis. A, B: images of the glass feeders filled with infected blood meals over black mesh clothing for retaining the mosquitoes inside the feeding cages; A: the glass feeder is covered with an artificial membrane and piece of parafilm; $\mathrm{B}$ : a glass feeder covered with a natural membrane, dissected chicken skin. The lateral side of the glass feeders (asterisks) are linked to aquarium tubings (not showing) for maintaining the circulating warm water. Inside the feeding cages, several mosquitoes are seen in the feeding activity (arrows in A and B).

assays evaluating the infectiousness to An. gambiae and concluded that the infection rates were similar with both methods. The membrane assay to infect mosquitoes is a simple method and can easily be applied in a laboratory without any sophisticated or complex devices.

From P. vivax infected patients to Amazon mosquito vectors - Today, it is possible to infect Amazon vectors in laboratories located in Manaus, the capital city of AM. The collaboration between three institutions, namely National Institute for Amazonian Research, Amazonian Oswaldo Cruz Foundation and Doctor Heitor Vieira Dourado Foundation for Tropical Medicine (FMT-HVD), has provided good conditions for developing important studies related to Plasmodium interaction with mosquito vectors. $P$. vivax is one of the most important causative agents of malaria in humans and is the most widespread and present parasite in America (Cruz et al. 2013); therefore, we decided to focus on its interaction with mosquito vectors. We used blood samples from adult vol- 
unteers (ages $>18$ years) infected with $P$. vivax for our experiments and diagnosed malaria using thick blood smears stained with Giemsa stain. Approximately $3 \mathrm{~mL}$ of blood were collected from volunteers by venipuncture. After blood collection, all the patients were treated at the FMT-HVD or in the health posts where they were diagnosed, following ethical procedures determined by the Brazilian Health Ministry.

A simple experimental protocol was used to infect the mosquito vectors (Figs 4, 5). Briefly, adult mosquitoes were sugar-starved overnight prior to infection. Blood samples infected with $P$. vivax were offered to the mosquitoes for a period of 45-90 min via a membrane-feeding assay through a glass feeder device (Figs 4B, 5A, B). A Parafilm ${ }^{\circledR}$ membrane was used to cover the glass device (Fig. 5A). Other natural membranes that can also be used for the experiments include the skin from two-three day-old chicks (Figs 4B, 5B) or from young mice or hamsters. During the experimental infection, blood was held at $37-39^{\circ} \mathrm{C}$ through a hose system connected to a thermal bath (Fig. 4A). Engorged mosquitoes were separated in rearing boxes. Five-eight days after ingesting infective blood meals, the midguts from the experimentally infected mosquitoes were dissected in phosphate buffered saline (PBS), stained with $\%$ commercial mercurochrome (Merbromin), placed under a cover glass and examined for the presence of oocysts. Additionally, 12-14 days after infection, the mosquito salivary glands were dissected in PBS in order to observe the sporozoites.

Improving the knowledge of the vectorial competence of Amazonian anopheline populations to Plasmodium is necessary to better understand the transmission of malaria in the region. At the end of 2013, our group published an article showing the characteristic aspects of the experimental P. vivax infection of key Anopheles species from the Brazilian Amazon and other surrounding South American countries (Ríos-Velasquez et al. 2013). This study compared the infection of four field-captured anophelines with the colonised An. aquasalis. The following mosquito species were studied: (i) An. darlingi, the major malaria vector in all countries located in the Amazon Region, (ii) An. aquasalis and An. albitarsis s.l., also proven vectors, and (iii) An. nuneztovari s.l. and An. triannulatus s.l., which have been found to be infected, but their status as vectors is not yet well defined. Larvae from the anophelines were collected in the field and reared until the adult stages, except for An. aquasalis, which was obtained from a well-established colony. All Anopheles species tested were susceptible to experimental $P$. vivax infection with the patient isolates. However, the proportion of infected mosquitoes and the infection intensity measured by oocyst number varied significantly among the species. Colonised An. aquasalis mosquitoes showed the highest infection intensity. It was also observed that the components of the serum (by way of inactivation) could modify the infection rates, increasing the infection in An. darlingi and An. triannulatus s.l., but diminishing infection in An. albitarsis s.l. and An. aquasalis. The gametocyte density in the infected blood meal varied among the mosquito species. An. albitarsis s.l., An. aquasalis and An. nuneztovari s.l. had higher in- fection rates than An. darlingi. This study was the first to characterise the experimental development of $P$. vivax in Anopheles vectors from the Amazon. The data found enabled us to infer that the $P$. vivax-vector interaction presents variations depending on the species analysed (Ríos-Velasquez et al. 2013). This fact could have a direct impact on the vector competence of the anopheline species. Moreover, this comparative study demonstrated and endorsed An. aquasalis, the main vector in coastal South and Central America, as a feasible laboratory model. Both An. aquasalis, from an established colony, and $P$. vivax, from malarial patients, are now being used by our group as a model of human malaria transmission (Bahia et al. 2010, 2011, 2013, Ríos-Velasquez et al. 2013).

The cultivated P. falciparum parasite and mosquito vector interaction - P. falciparum is the human malaria parasite with the most devastating clinical consequences. In laboratories located close to the endemic regions, it is possible to study the interaction of $P$. falciparum with mosquito vectors by feeding the mosquito with collected infected blood from local patients (Harris et al. 2012). However, with the introduction of the continuous culture of $P$. falciparum, it is now possible to study the factors involved in parasite-vector interactions in the laboratory far from the endemic areas. The first successful continuous culture was established and described by Trager and Jensen (1976).

The adaptation of several lines of $P$. falciparum-producing gametocytes in laboratories allowed the infection of colonised mosquito vectors (Trager \& Jensen 1976, Carter $\&$ Miller 1979). Several studies have been performed by distinct research groups allowing the characteristics of $P$. falciparum inside some important vectors from Africa and Asia, including the molecular aspects of the interaction and the immune response to the parasite infection to be understood (Rodrigues et al. 2012, Ramirez et al. 2014). Additionally, studies have shown that mosquito species exhibit a wide range of susceptibility to infection with a given P. falciparum line (Collins et al. 1986, Lambrechts et al. 2005) and different Plasmodium isolates also vary in their ability to infect a given mosquito strain (Niare et al. 2002, Lambrechts et al. 2005, Riehle et al. 2006).

A degree of adaptation was suggested between geographically isolated populations of An. gambiae and $P$. falciparum when an An. gambiae colony was successfully selected for resistance to New World P. falciparum isolates, but remained susceptible to those of African origin (Collins et al. 1986). Different vector-parasite interactions may have evolved through adaptation in the African An. gambiae and P. falciparum, allowing this parasite population to evade the mosquito's immune response (Lambrechts et al. 2007). African and New World $P$. falciparum populations show moderate genetic divergence (Volkman et al. 2007, Jambou et al. 2010) that could drive the differences in their infectivity. It appears that genetic differences in both the mosquito and the parasite affect the efficiency of mosquito infection and disease transmission (Molina-Cruz et al. 2012). Recent studies show that Brazilian and African lines (7G8 and NF54, respectively) infecting An. gambiae (African vector) differ in their ability to evade the mosquito's im- 
mune system and thioester-containing protein 1 (TEP1) (a complement like system) is correlated with parasite invasion (Molina-Cruz et al. 2012). Also of interest is an article demonstrating that $P$. falciparum development in a non-malaria vector, Culex quinquefasciatus, is blocked by the mosquito immune response after ookinetes have crossed the midgut epithelium and come in contact with the mosquito haemolymph (Molina-Cruz et al. 2013).

The identification of Brazilian P. falciparum lines that produce infective gametocytes will provide important information that will elucidate the parasite/vector interaction that is indispensable for future studies aimed at developing new strategies for blocking malaria transmission. The susceptibility of An. aquasalis and An. darlingi to this parasite under laboratory conditions needs to be further investigated.

Non-human Plasmodium species as a model for studying the interaction with mosquito vectors - P. berghei, $P$. yoelii and Plasmodium chabaudi are murine parasites that have been adapted in the laboratory and are considered good models to investigate malaria in mammals and also to study parasite-mosquito interactions. These Plasmodium species have been used in different laboratories for several years to infect An. gambiae, Anopheles funestus, An. quadrimaculatus and An. stephensi, all of which are malaria vectors in Africa and Asia, mainly due to the vectors' high susceptibility to infection with various malaria parasite species and strains (Yoeli et al. 1964, Vaughan et al. 1991, Sinden et al. 2002, Alavi et al. 2003, Akaki \& Dvorak 2005, Frischknecht et al. 2006, Hume et al. 2007, Lo \& Coetzee 2013, Xu et al. 2013).

There are several advantages of using an animal model of malaria and many research groups worldwide have begun using murine Plasmodium-based experimental models to better understand the interaction between malaria parasites and vectors. Essentially, these models have been helpful in the evaluation of potential interventions for malaria control and to generate and test hypotheses about the biology of human malaria and drug tests (Killick-Kendrick 1978, Jaramillo-Gutierrez et al. 2009, Xu et al. 2013).

$P$. berghei was first found in the gut and salivary glands of Anopheles dureni (its natural invertebrate host) in Central Africa. Later, the parasite was isolated from the vertebrate host, the tree rat, Grammomys surdaster, before being was passed on to white rats and resulting eventually in the K173 strain (Vincke 1954, Yoeli 1965, Sinden et al. 2002). P. berghei has largely been used as a reliable experimental model for malaria studies because of its relatively simple requirements for laboratory maintenance and the availability of permanent green fluorescent-labelled strains (Franke-Fayard et al. 2004). Consequently, P. berghei is one of the most commonly studied Plasmodium species, particularly for elucidating the interactions between the parasites and their hosts (Anderson et al. 2004, Baldacci \& Menard 2004, Ishino et al. 2004, Levashina 2004, Siden-Kiamos \& Louis 2004). P. yoelii was originally found and isolated from rats in Central Africa. Three subspecies are recognised, namely $P$. yoelii yoelii, $P$. yoelii nigeriensis and
P. yoelii killicki, and they are widely used to study host immune responses and the genetic basis of parasite phenotypes. $P$. chabaudi is a parasite of the African thicket rat, Thamnomys rutilans; it has been adapted to develop in the laboratory mouse and is one of the best laboratory models for the study of malaria. The species is one of the most common murine models that have been utilised within vaccine research. $P$. berghei and $P$. yoelii transgenic lines that constitutively express green fluorescent protein (GFP) can develop throughout the entire life cycle in the vertebrate host and these mosquito vectors have been very useful in laboratorial experiments.

$P$. gallinaceum is an avian malaria parasite that is phylogenetically closer to $P$. falciparum than it is to many other malaria species (McCutchan et al. 1996, Roy \& Irimia 2008) and has intriguingly become very useful in laboratories because it can be infected and complete its entire cycle in Ae. aegypti mosquitoes and in Aedes fluviatilis (Tason \& Krettli 1978, de Camargo et al. 1983, Pimenta et al. 1994, Gupta et al. 2005). This model is now widely used for understanding the cell biology of parasitic infection and the routine chemotherapy test in chicks (Carvalho et al. 1992, Rocha et al. 1993a, b, Ramirez et al. 1995, Krettli et al. 2001, da Rocha et al. 2004, Maciel et al. 2008, Rodrigues et al. 2008).

Few studies regarding New World vectors have been developed to date. An. albimanus, a Central America malaria vector, can be infected by $P$. yoelii, but cannot be effectively infected by $P$. berghei (Vaughan et al. 1994, Noden et al. 1995, Brucker \& Bordenstein 2013). However, Frischknecht et al. (2006) demonstrated that a transformed GFP-P. berghei line can complete its life cycle in this North American vector. However, the susceptibility of two important human malaria vectors of this parasite in South America, An. aquasalis and An. darlingi, requires further investigation under laboratory conditions. It was recently shown that An. funestus, an important vector in Sub-Saharan Africa, is permissive for $P$. berghei development, which is in contrast with previous reports (Xu et al. 2013). This kind of work highlights the importance of fully testing New World anopheline species for $P$. berghei experimental infections using different parasite strains and mosquito populations.

The establishment of experimental infections using An. aquasalis mosquitoes from colonies and P. yoelii and $P$. berghei parasites could provide an interesting model for studying malaria in the Amazonian scenario. It could definitely be the first step in finally understanding the biology underlying $P$. vivax and/or P. falciparum infection of Brazilian vectors.

\section{The immune response of the mosquito vector to Plasmodium infection}

Understanding the molecular mechanisms involved in the development of the parasites in the vectors is an important step in determining the interaction process and vectorial competence. Mosquitoes, like other organisms, produce humoral and cellular immune responses. A large range of molecules can be produced against pathogens such as bacteria, fungi, viruses and Plasmodium spp and can be secreted by mosquito or- 
gans and tissues as fat bodies, haemocytes and midgut cells (Yagi et al. 2004, Cirimotich et al. 2010). Recent studies using microarrays and transcriptome techniques have described how Plasmodium parasites can modulate the expression of immune genes in An. gambiae and An. stephensi (Dimopoulos et al. 2002, Xu et al. 2005, Dong et al. 2006, Baton et al. 2009). Actually, many studies have produced evidence supporting the fact that the vectorial competence of a determined vector depends on the action of the mosquito immune system during the infection process with Plasmodium species.

During several steps of the life cycle, mosquito immune defences can kill parasites, thereby controlling or eliminating the infection. Once Plasmodium parasites are ingested by female mosquitoes during blood feeding, they face the harsh environment of the digestive tract. It has been previously observed that these parasites can negatively or positively modulate the gene expression and activity of many of the mosquito's digestive enzymes (Gass \& Yeates 1979, Jahan et al. 1999, Somboon \& Prapanthadara 2002). There are several phenomena related to the mosquito vector's defences that can occur. For example, the production of nitric oxide synthase (NOS) by the vector occurs from the period before the invasion of the intestinal epithelium to the time when the parasite crosses the epithelial cells. NOS is responsible for activation of the production of the antimicrobial peptides that are responsible for the death of a large number of ookinetes in the insect gut (Luckhart et al. 1998, Dimopoulos et al. 2001, Olayan et al. 2002, Herrera-Ortiz et al. 2011). Moreover, NOS is also an important component of the nitration process in Plasmodium-invaded midgut cells and targets parasites for complement activation through TEP1 protein (Oliveira et al. 2011). Additionally, due to this immune response (at least for the human Plasmodium), less than 10 ookinetes can successfully cross the intestinal epithelium and form viable oocysts (Ghosh et al. 2000). This means that only a small proportion of the ingested parasites will be able to successfully escape the interior of the intestine, cross over the PM and invade the epithelial cells of the intestine. Activation of the melanisation cascade may also occur during the crossing of the intestinal epithelium. A cascade of serine proteases which activates PPOs through a second cascade leads to the deposition of melanin and free radicals that are involved in the death of ookinetes (Luckhart et al. 1998, Hoffmann et al. 1999, Ghosh et al. 2000, Ligoxygakis et al. 2002, Cirimotich et al. 2010). The ookinetes that survive the onslaught of the immune system will release the sporozoites. In the haemolymph, the phagocytosis of sporozoites by mosquito haemocytes has been described in Ae. aegypti and An. gambiae (Hillyer et al. 2003, 2007). In addition to their phagocytic activity, these haemocytes are able to secrete substances that assist in promoting the death of the parasite (Blandin \& Levashina 2007). Antimicrobial peptides that are rapidly produced by the fat body of the insect also represent an important step in fighting the infection. Actually, there is an intensive role that the mosquito's immune system has to constantly undergo in order to fight back the infection.
The insect's defense mechanisms are activated by intracellular immune signalling pathways. Toll, immunodeficiency (IMD) and JAK/STAT are the three major immune pathways, first described in Drosophila and then in Anopheles (Cirimotich et al. 2010). The Toll pathway activation by $P$. berghei is able to restrain parasite survival in An. gambiae (Frolet et al. 2006). Over-activation of this pathway by silencing the negative regulator cactus dramatically reduced $P$. berghei loads in An. gambiae, An. stephensi and An. albimanus, but not P. falciparum numbers in these same mosquito species (Garver et al. 2009). Interestingly, the IMD pathway plays an important role in limiting P. falciparum infection. Depletion of caspar, the negative regulator of the IMD pathway, promotes a P. falciparum-refractoriness phenotype in An. gambiae mosquitoes. However, the same phenotype is not achieved when P. berghei is used (Garver et al. 2009).

In An. gambiae, the JAK/STAT pathway mediates the killing of $P$. falciparum and $P$. berghei in the late infection phases after midgut invasion. Disruption of this pathway by silencing the transcription activator, STAT-A, promotes $P$. berghei oocyst development. Meanwhile, the over-activation of the JAK/STAT pathway by depletion of the suppressors of cytokine signalling triggers NOS expression and decreases the infection levels (Gupta et al. 2009).

Reactive oxygen species (ROS) are generated by mitochondrial activity and/or activation of the immune system in mosquitoes (Kumar et al. 2003, Molina-Cruz et al. 2008, Gonçalves et al. 2012). In An. gambiae, the ROS-producing dual oxidase protein and an haemeperoxidase (HPX2) are able to secrete a dityrosine network. This network prevents strong immune activation of the midgut by commensal gut bacteria. When Plasmodium ookinetes invade epithelial cells, the dityrosine network is disrupted and a high level of NO, which has a strong negative effect on parasite survival, is produced (Kumar et al. 2010). In addition, the invasion of the An. gambiae midgut epithelium by the $P$. berghei ookinetes induces the expression of a nicotinamide adenine dinucleotide phosphate (NADPH) oxidase, NADPH oxidase 5 and HPX2, which catalyses protein nitration leading to parasite opsonisation and killing through complement action in the mosquito's haemolymph (Oliveira et al. 2011). Although ROS can promote parasite killing, they can also be hazardous to mosquito cells. Therefore, ROS production should be compartmentalised and their life-span must undergo fine regulation by the activation of detoxifying enzymes such as catalase and superoxide dismutase (SOD). In An. gambiae, catalase expression and activity is inhibited by $P$. berghei infection. The silencing of this enzyme decreases $P$. berghei survival (Molina-Cruz et al. 2008), emphasising that ROS are important immune effectors against Plasmodium parasites.

Another major process in insect defense is the melanisation immune response that is present in the major classes of arthropods. Factors present in the haemolymph mediate melanin synthesis when the recognition of non-self is activated and a CLIP cascade culminates in the limited proteolysis and conversion of inactive prophenoloxidase proenzyme (PPO) into active phenoloxi- 
dase (PO). Subsequent oxidation of phenols by PO leads to the production of quinones that polymerise to form melanin. Several serine proteases have been identified and characterised in the haemolymph of Anopheles in the presence of Plasmodium. Changes in the conformation of some membrane receptors activate a serine protease, which in turn triggers the activation of the PPO cascade that activates the melanisation immune response. $\mathrm{PO}$ is a very active enzyme and its activation intermediates are toxic both to invading microorganisms and for the insect itself. Therefore, its activation is limited to the site of infection and if not, it could lead to widespread and lethal melanisation for insects. In the plasma and haemocytes, inhibitory proteins such as serpins (SRPNs) can be found that regulate the activity of serine proteases (Volz et al. 2006). In mosquitoes, SRPNs regulate the cascade of PPO and determine whether or not malaria parasites are lysed, mainly via the activation of the Toll and IMD pathways (Gulley et al. 2013).

Many functional genetic studies have demonstrated in the An. gambiae/P. berghei system that melanisation can eliminate dead ookinetes (Blandin et al. 2004) or directly mediate ookinete killing, based on the mosquito's genetic background (Volz et al. 2006). The melanisation response of Plasmodium has been particularly followed in refractory mosquitoes such as the An. gambiae strain (L35), which melanises most Plasmodium species including the Brazilian P. falciparum 7G8 line; it is highly susceptible to some African $P$. falciparum strains such as LE5 and NF54 (Collins et al. 1986). Recently, Molina-Cruz et al. (2013) investigated whether these parasite lines differed in their ability to evade the mosquito's immune system. Silencing key components of the mosquito's complement system (TEP1, LRIM1 or APL1) prevented melanisation of $7 \mathrm{G} 8$ parasites, reverting to the refractory phenotype. In contrast, it had no effect on the intensity of the infection with NF54, indicating that this line is able to evade the mosquito's complement system. Furthermore, when L35 females were co-infected with a line that is melanised (7G8) and one that survives (3D7), this resulted in mixed infections with both live and encapsulated parasites in individual midguts. The African 3D7 parasites were able to evade the mosquito complement system even when 7G8 parasites were being melanised, indicating that immune evasion is parasite-specific and not systemic in nature. These findings suggest that evasion of the An. gambiae immune system by P. falciparum may be a result of parasite adaptation to sympatric mosquito vectors and may be an important factor driving malaria transmission (Molina-Cruz et al. 2012).

In the interaction studies of Plasmodium with their vector, more attention has been paid to the TEP1 that has a similar structure to that of vertebrate $\mathrm{C} 3$. Mosquito haemocytes synthesise and release TEP1 in the haemocoel. TEP1 acts as an opsonin, promoting the phagocytosis of Gram-negative and Gram-positive bacteria in a thioester-dependent manner (Levashina et al. 2001). It was also observed that TEP1 can bind and mediate the killing of the midgut stages of $P$. berghei parasites (Blandin et al. 2004) and efficient binding of TEP1 to the ookinetes requires previous parasite targeting by mid- gut protein nitration (Oliveira et al. 2011). Specifically, TEP1 binds to the surface of the P. berghei ookinetes escaping from the basal side of the mosquito midgut epithelium, mediating the death of the parasite (Blandin et al. 2004). Moreover, TEP1-depleted susceptible and refractory (L35) An. gambiae mosquitoes showed enhanced development of Plasmodium oocysts, clearly demonstrating its anti-parasitic effect (Blandin et al. 2004) for P. berghei (Molina-Cruz et al. 2012) and for $P$. falciparum. Considering the LRIM1, LRR and APL1C cited in the above paragraph that also displayed a similar knock-down phenotype to that of TEP1 and increased $P$. berghei oocyst numbers in susceptible and L35 refractory mosquitoes, as well as inhibiting ookinete melanisation (Osta et al. 2004, Riehle et al. 2008, Povelones et al. 2009), there is a functional collaboration between these three proteins in mosquito anti-parasitic defence. Further studies of these complex molecules are necessary for a complete understanding of the innate immunity of these malarial vectors.

Haemocytes are the main players of the insect cellular response. The haemocyte types can vary greatly from flies to mosquitoes (Blandin \& Levashina 2007). In An. gambiae, the main haemocyte populations are prohaemocytes, progenitor cells, granulocytes, phagocytic cells and oenocytoids (Rodrigues et al. 2010). They are responsible for the melanisation and encapsulation of pathogens in the haemolymph. In addition, haemocytes can also produce humoral effectors that target Plasmodium parasites (Pinto et al. 2009). Recent studies have demonstrated that different Plasmodium species can trigger haemocyte differentiation in An. gambiae (Ramirez et al. 2014) and an increase in the granulocyte population is associated with immune protection towards subsequent P. berghei infections (Rodrigues et al. 2010).

The Plasmodium life cycle is a complex process and one could argue that this complexity is due to the parasite's ability to alter itself on a cellular and molecular level. Recent studies have determined that the expression of Plasmodium surface proteins can control the vector infection. The $P$. falciparum gamete surface protein genes $P f_{s} 48 / 45$ and $P f_{s} 47$ have been shown to have highly polymorphic regions (Conway et al. 2001, Anthony et al. 2007). Population studies have demonstrated an extreme geographical divergence of allele frequencies for both the $P f_{s} 48 / 45$ and $P f_{s} 47$ genes. This strong population structure is not observed in other P. falciparum genes. The $P f_{s} 48 / 45$ and $P f_{s} 47$ genes have seven and 18 single nucleotide polymorphisms (SNPs), respectively, while other genes have fewer SNPs. The African lines had the most diverse combinations of these genes, whereas parasites from Brazil and Peru have the same SNP combination. Recently, Molina-Cruz et al. (2013) identified $P f s 47$ as an essential survival factor for $P$. falciparum that allows the parasite to evade the immune system of An. gambiae. $P f_{s} 47$ suppresses midgut nitration responses that are critical in activating the complement-like system. Thus, the disruption of $P f_{S} 47$ reduced parasite survival in the mosquito. These authors also provide evidence that $P f_{S} 47$ population structure may be due to the adaptation of $P$. falciparum to different Anopheles vector species present 
outside of Africa. Understanding the molecular mechanisms involved in this step is crucial to interfering with the development of Plasmodium in mosquitoes.

\section{Immune response of $A n$. aquasalis to $P$. vivax infection}

Because the genome sequence of this mosquito is still not available, differential subtraction mRNA libraries were generated to investigate how $P$. vivax infection modulates An. aquasalis gene expression (Bahia et al. 2010). Infection down-regulated the expression of the genes related to mosquito embryogenesis and energy metabolism, which was consistent with the notion that the activation of the immune system towards Plasmodi$u m$ has a negative impact on reproductive fitness (Hopwood et al. 2001, Ahmed \& Hurd 2006). In contrast, only $3 \%$ of the obtained sequences were related to immunity. This weak immune activation could be associated with a high compatibility between $P$. vivax and An. aquasalis, as demonstrated for other parasite-vector combinations (Jaramillo-Gutierrez et al. 2009).

Regarding the harsh environment of blood digestion in the P. vivax-An. aquasalis model, the expression of a chymotrypsin-like protease was heavily inhibited by infection $24 \mathrm{~h}$ after this infection occurred, showing that the parasite can negatively modulate this gene expression. The same effect was not observed for a carboxypeptidase A-like protein also found in this anopheline (Bahia et al. 2010). However, P. vivax infection induced the expression of a member of the SRPN family. These are classical inhibitors of serine proteases that participate in blood digestion and the melanisation cascade (Dana et al. 2005, Michel et al. 2005). It is still unclear, however, whether these changes in digestive enzymes could have a protective effect on $P$. vivax development in An. aquasalis mosquitoes.

In P. vivax-infected An. aquasalis, catalase and SOD expression was induced $36 \mathrm{~h}$ post-infection (p.i.) in the whole mosquitoes. This induction was not observed in the infected midguts. However, midgut catalase and SOD activities were significantly lower $24 \mathrm{~h}$ after infection, indicating that $P$. vivax parasites can modulate the detoxifying response post-transcriptionally (Bahia et al. 2013). The silencing of catalase increased $P$. vivax infection and prevalence. These results are in contrast with previous reports for An. gambiae (Molina-Cruz et al. 2008) and suggest that ROS are necessary for $P$. vivax development in An. aquasalis mosquitoes, leading this parasite to manipulate the detoxification system accordingly.

The role of IMD and Toll pathways on the P. vivaxAn. aquasalis interaction remains unclear. $P$. vivax can induce the expression of the antimicrobial peptide cecropin in An. aquasalis mosquitoes (Bahia et al. 2010) and cecropin production is under the control of IMD and Toll pathways in other mosquito species (Meister et al. 2005, Moon et al. 2011, Pan et al. 2012).

Bahia et al. (2011) showed that the JAK/STAT pathway is also activated in $P$. vivax-infected An. aquasalis mosquitoes, but at an earlier stage than previously reported for An. gambiae (Gupta et al. 2009). The expression of STAT, the negative regulator protein inhibitor of activated
STAT1 and the immune effector NOS was induced by Plasmodium at 24 and $36 \mathrm{~h}$ p.i. NOS is an important component of the nitration process that targets parasites for complement activation (Gonçalves et al. 2012). Besides to silencing of STAT promoted P. vivax development in An. aquasalis mosquitoes. The effect of the STAT pathway on $P$. vivax infection at later stages is yet to be investigated.

\section{Consideration of anopheline genomes and those of New World vectors}

The 2002 publication of the An. gambiae sensu stricto (Holt et al. 2002) and the P. falciparum (Gardner et al. 2002) genomes marked a breaking point in the field of malaria vector biology research. The Anopheles project wrapped together decades of classic genetics knowledge, allowing us to better understand issues such as chromosome and gene architecture. It also allowed vector biologists to plunge into the area of comparative genomics through which the first comparisons made (Christophides et al. 2002, Zdobnov et al. 2002) addressed matters such as the composition of the immunity-related gene repertoire. In the post-genome era, several genetic engineering tools and strategies for vector control have arisen, have been implemented and have been assessed (Alphey et al. 2002, Lycett \& Kafatos 2002, Scott et al. 2002, Benedict \& Robinson 2003, Riehle et al. 2003, Tabachnick 2003, Toure et al. 2004, Sinkins \& Gould 2006, Takken \& Knols 2009, Isaacs et al. 2011, Sumitani et al. 2013). Nevertheless, the high diversity and plasticity that Plasmodium parasites have shown in vertebrate and invertebrate hosts have led to the assumption that the parasites evolve faster and adapt rapidly, more so than human and anopheline hosts (Carius et al. 2001, Cohuet et al. 2010). As a consequence of this phenomenon and with the experiences thus far accumulated, the vector biology community understood that sequencing the genomes of multiple mosquito and parasite species would be imperative to understanding and manipulating the vector-parasite interactions.

For this purpose, efforts were jointly channelled via the Anopheles Genomes Cluster (AGC), which in 2008 formed the basis of what would become the first anopheline comparative genomics consortium (Besansky 2014). The committee identified and selected 16 mosquito species whose genomes and transcriptomes were about to be published (Neafsey et al. 2013) and made available through the VectorBase (Megy et al. 2012). Unfortunately, An. albimanus is the only American vector listed in the project and no attention was paid to the Amazon mosquitoes that are the vectors of the majority of the human cases on the continent.

The evolutionary vector-parasite dynamics, vectorial competence traits and mosquito behaviour could have been shaped by multiple factors such as specific genotype combinations. Experimental evidence and theories explaining how the genomic composition of a mosquito species determines whether it is refractory or susceptible towards infection by a species (strains) of Plasmodium parasite have been published (Billingsley \& Sinden 1997, Norris et al. 2001, Osta et al. 2004, Lambrechts et al. 2005, Riehle et al. 2007, Jaramillo-Gutierrez et al. 
2009, Harris et al. 2010). There is also a great body of literature connecting vector biology with non-genetic components such as ecological factors (Schmid-Hempel \& Ebert 2003, Lambrechts et al. 2005, Tripet et al. 2008, Tripet 2009, Wolinska \& King 2009).

As stated by the AGC (Moreno et al. 2010, Besansky 2014), sequencing the genome of mosquito species that capture and represent the evolutionary and phenotypic divergence within the anopheline vectors distributed throughout the world is critical. It is the consensus among the community that envisioning a eukaryote genome project requires looking at it as a continuous process of innovation, re-sequencing and annotation $(\mathrm{Li}$ et al. 2006, 2010, Sharakhova et al. 2007, Moreno et al. 2010). Together with the An. gambiae s.s. genome, other annotated anopheline assemblies will provide a platform for gaining genome-wide evolutionary and population genetic insights into the mechanisms of speciation and the biological processes that influence the ability of the mosquitoes to transmit malaria parasites to humans.

It has also been brought to the attention of the vector community that the genomic aspects of vectorial capacity and competence have not been uniformly studied (Cohuet et al. 2006, 2010) and some have been largely overlooked, both in terms of the species analysed and the gene families addressed by experimental biology. For example, rapid progression has been made regarding mosquito immunity, insecticide resistance and olfaction genetics. However, the genetic determinants of parasite virulence, mosquito adaptation to human environments and the evolutionary forces exerted on vectors by the parasite and the microbiome associated with them, are still progressing slowly. The area of comparative genomics is rapidly evolving and developing tools. Therefore, the number of questions that vector biology can answer through sequenced and published genomes has expanded (Zdobnov et al. 2002, Reddy et al. 2012). Major analytical themes now include topics such as molecular evolution and speciation, chemoreception, circadian rhythm, development, repetitive and transposable elements, reproduction, secretomes, rearrangements of chromosomal architectures, neuropeptides and behaviour, blood/sugar metabolism and so on.

The Neotropical vectors represent an interesting target to understand how competent malaria transmission evolved in a different ecological setting and also followed different human settling conditions (Fagundes et al. 2008, Hubbe et al. 2010, O'Rourke \& Raff 2010, Bodner et al. 2012, Yalcindag et al. 2012). It is believed that the interactions between the actors of the malaria transmission triad - humans, Neotropical vectors and Plasmodium parasites - are relatively recent on the American continent. For example, the main Neotropical malaria vector, An. (Nyssorhynchus) darlingi, which diverged from An. (Cellia) gambiae approximately 100 million years ago, could have evolved in a human and parasite-free environment for several million years (Moreno et al. 2010).

When we add up all of the biological evidence and take into account the fact that malaria is a malady that still imposes a high burden upon the people who live in the Amazon Basin ( $>500$ thousand cases are reported annually), sequencing the genome of a Neotropical vector seems important. Thus, in 2013, this became a reality with the publication and upload onto the VectorBase of the An. darlingi genome (Marinotti et al. 2013). This project was performed at the behest of the Brazilian National Council for Research and set a cornerstone for future basic and applied comparative genomics studies. Such research endeavours will be able to start answering long sought-after answers regarding the biology of malaria in an American context and will focus on generating genetic and chemical tools (e.g., insecticides, bacterial larvicides and paratransgenesis strategies) for vector control that better adjust to the ecological and public health conditions in Latin America.

The Brazilian malaria research network is aware of the pitfalls that were addressed and elegantly presented by the AGC regarding the ordeals of the de novo assembly of complex eukaryote genomes. Critical aspects of genome sequencing and assembly have been proposed for discussion in the vector biology community due to the open nature of the AGC work. Such topics include: the necessity of isogenic colonies, DNA template quality, genomic library building techniques and heterozygosity-solving algorithms, amongst others. It is the opinion of the Brazilian malaria research network that the time is right to embark on the establishment of a suitable model for research that benefits from the experience and data generated by the An. darlingi genome and together expands and enriches the depth of knowledge of American vector biology.

As proof of the steps being taken by research groups in Brazil towards the advancement of genomic sciences, we can also mention the ongoing An. aquasalis genome project. This will bridge the vacuum that currently exists between the An. darlingi model and its use in experimental biology research. The absence of colonies of this species in several laboratories and the highly heterozygous nature of its genome assembly still hinder its potential as a research model.

The An. aquasalis species has viable, operating colonies throughout Brazil. It is pertinent that An. aquasalis has been used in experimental infections and transmission assays with multiple Plasmodium species. Therefore, this species is positioned as a top model for the understanding of malaria transmission within the Brazilian context. The peculiar bionomics of the An. aquasalis mosquito (Sinka et al. 2010) has prompted us to expand and explore other "genomic" areas, in particular the reconstruction of the associated consortium of bacteria and viruses that could be predicted from the massive parallel sequencing process is of interest. Next Generation Sequencing (NGS) technology has evolved into an impressive tool that ranges from genome assembly to microbiome screening (Mardis 2011). When carefully implemented and combined with the experimental designs of genome sequencing projects, metagenomics could become a key element to deconvolute the complex inner insect ecosystem.

As a final thought, we believe that tailored measures of vector control that respond to local conditions and transmission patterns are sorely needed in our region. Targeted interventions based on the growing existence of genomic data pertaining to tandems of Neotropical 
vectors and Plasmodium parasites could enhance the control strategies that already exist. Building the capacity to generate and use comparative genomics data from local anopheline species is therefore justified.

\section{Modulation of Plasmodium infection by the mosquito vector microbiota}

Amongst the metazoans, insects are by far the most diverse and abundant clade (Basset et al. 2012). Their success can be explained in part by the relationships they have established with beneficial members of their associated microbiome. The term microbiota defines the microbial communities that stably or transiently colonise insect epithelia as well as intracellular compartments and target organs. They may vary from bacteria to viruses, yeasts and protists. The bacterial component of this ecosystem is to date the most studied and characterised (Ng et al. 2011a, Gendrin \& Christophides 2013, Minard et al. 2013). These symbiotic microbiomes or consortiums are beneficial for their insect hosts in many ways (Dillon \& Dillon 2004, Azambuja et al. 2005, Thomas et al. 2012, Engel \& Moran 2013), including the following: as dietary supplementation, for the enhancement of digestive mechanisms, to help tolerate environmental perturbations, for protection from parasites (Degnan \& Moran 2008) and pathogens (Nartey et al. 2013) and for the maintenance and/or enhancement of host immune system homeostasis. Furthermore, the absence or elimination of the microbial fauna and even the modification of its composition can reduce the fitness of the harbouring insect (Thomas et al. 2012). This observed influence of the microbiome on its host has been referred to as the extended phenotype and can range from mutualism to parasitism, as well.

Recently, the study of microorganisms living in the insect gut has increased considerably. The last decade has seen the publication of multiple relevant studies ranging from diversity screening metagenomic surveys (Baumann 2005, Lindh et al. 2005, Carpi et al. 2011, Dinparast et al. 2011, Lindh \& Lehane 2011, Ng et al. 2011a, b, Chavshin et al. 2012) to molecular studies on how the gut bacteria interact with the host's immune system and respond to infection (Azambuja et al. 2005, Chouaia et al. 2010, Boissiere et al. 2012).

It is not within the scope of this review to provide an exhaustive analysis on metagenomics or the architecture and dynamics of this micro-ecosystem within Culicine vectors. Recent revisions cover these topics substantially and creatively (Dillon \& Dillon 2004, Engel \& Moran 2013, Gendrin \& Christophides 2013, Minard et al. 2013). Our aim is to briefly call attention to recent advancements that malaria vector control has generated regarding microbiota and its association with vector competence traits. Many of them have been greatly enhanced by the use of metagenomic tools that have allowed us to discover and explore how microbial species could be used in paratransgenesis and malaria transmission-blocking strategies.

Metagenomics emerged as a derivation of classic microbial genomics with the key difference being that it bypasses the requirement for obtaining pure cultures for sequencing (Glass et al. 2010, Huttenhower 2012, Kim et al. 2013). We now have the ability to obtain genomic informa- tion directly from microbial communities in their natural habitats and study them in a concerted manner, describing their species composition and even predicting the potential genomic functions and metabolic capabilities they possess (Wooley et al. 2010, Williamson \& Yooseph 2012).

As NGS has skyrocketed, our potential to generate genomic data benchmarking (Ansorge 2009) has gained relevance, providing guidance to experimental biologists that encounter themselves with a myriad of available bioinformatics tools (Delcher et al. 2007, Huson et al. 2007, Meyer et al. 2008, Angly et al. 2009, Clemente et al. 2010, Glass et al. 2010, Gerlach \& Stoye 2011, Jiang et al. 2012). As users of such technology, we would like to stress that when designing experiments that encompass metagenomic data generation, it is imperative to consider points such as: sampling techniques, DNA/RNA extraction protocols, sequencing platforms, assembly, taxonomic binning, gene annotation tools, statistical analysis and data/meta-data sharing formats (Wommack et al. 2008, Tanenbaum et al. 2010, Wooley et al. 2010, Thomas et al. 2012). The availability of standardised procedures (Field et al. 2008, Tanenbaum et al. 2010) and platforms for data storage and sharing are becoming increasingly important to ensure that the output of individual projects can be assessed and compared (Thomas et al. 2012).

Metagenomic screening assays are now being used to determine the diversity of microorganisms and viruses residing in arthropod vectors of medical importance. Such assays allow human health agencies and research groups to monitor endemic infections, perform real-time surveillance of newly emerging zoonotic pathogens, discover etiological agents and discover how they associate with and within their host (Bishop-Lilly et al. 2010, Carpi et al. 2011, Ng et al. 2011a, b, Mokili et al. 2012).

Due to their importance as vectors of malaria, anopheline mosquitoes have been the targets of multiple efforts to profile their microbiota (Gendrin \& Christophides 2013). Behind this effort lies the knowledge that bacteria living in the midgut have been found to modulate the response of the mosquitoes towards Plasmodium infection (Pumpuni et al. 1993, Dong et al. 2009, Boissiere et al. 2012, Eappen et al. 2013), have the potential to block infections and can be used as genetic transformation vehicles (Pumpuni et al. 1993, Dong et al. 2009, Weiss \& Aksoy 2011, Boissiere et al. 2012, Ricci et al. 2012, Eappen et al. 2013). Below, we summarise some of the key findings regarding the impact of microbiota on the Plasmodium-Culicidae interaction model.

Both laboratory and field mosquito strains have been found to be associated with microbial organisms that particularly colonise the gut. They consist primarily of Gram-negative bacteria of the Enterobacteriaceae family. Field populations of An. gambiae and An. funestus were found to contain 16 bacterial species spanning 14 genera (Lindh et al. 2005). The laboratory populations of An. gambiae and An. stephensi also presented a wide variety of bacteria, especially of the genus Asaia, Enterobacter, Mycobacterium, Sphingomonas, Serratia and Chryseobacterium (Favia et al. 2007, Dong et al. 2009). Bacteria of the Asaia genus were also found in Ae. aegypti mosquitoes (Pidiyar et al. 2004, Rani et al. 
2009, Gaio et al. 2011). In addition, beyond the digestive tract, studies have shown that the species of this genus are also able to colonise the salivary gland and ovaries of mosquitoes and are usually acquired through vertical transmission (Favia et al. 2007).

It has been shown that gut bacteria may have an impact on vectorial competence by inhibiting the sporogonic development of malaria parasites within the mosquito vector (Pumpuni et al. 1993, 1996, González-Cerón et al. 2003, Dong et al. 2009, Cirimotich et al. 2011). Pumpuni et al. $(1993,1996)$ also showed, whilst manipulating the bacterial content, that Gram-negative bacteria inhibit oocyst formation in whole or in part and that the same action was not observed with Gram-positive bacteria.

Evidence of this influence of the intestinal microbiota on the life cycle of the parasites has been demonstrated for other insects such as sandflies and tsetse flies (Schlein et al. 1985, Welburn \& Maudlin 1999).

Recent studies suggest that Enterobacter species in the gut of Anopheles arabiensis mosquitoes originating from Zambia act directly on $P$. falciparum, blocking the development of the parasite and making this population refractory to infection. This refractoriness was associated with the generation of the ROS that interfere with the development of the parasite and kills it before its invasion of the intestinal epithelium (Cirimotich et al. 2011).

Previous studies suggest that bacteria in the gut lumen modify the intestinal environment and inhibit the development of parasites by the actions of the immune system by overexpression of immunity genes, culminating in an increased rate of production of antimicrobial peptides (Pumpuni et al. 1996, Ratcliffe \& Whitten 2004, Michel \& Kafatos 2005). Such peptides are likely to play a key role not only in the control of pathogenic or symbiotic bacteria, but also in the development of infections by parasites (Beard et al. 2001, Boulanger et al. 2004). Interestingly, the mosquito immune system acts against bacterial growth and also eliminates a large number of parasites modulating the intensity of infection in mosquitoes infected with $P$. berghei or P. falciparum (Meister et al. 2009).

It has also been proposed that certain bacteria taxa can induce a reductive environment within the mosquito midgut, thus aiding in the detoxification of reactive oxygen and nitrogen species, a fact that would allow for an aggressive immune response of the mosquito when infected by the parasite (Wang et al. 2011).

In Ae. aegypti, antibiotic treatment affects the progression of $P$. gallinaceum infection. It was observed that mosquitoes treated with kanamycin partially inhibited the sporogonic development of $P$. gallinaceum, while carbenicillin-treated mosquitoes were significantly more susceptible to infection. Although both antibiotics are effective against Gran-negative bacteria, carbenicillin also affects Gram-positive bacteria (AS Orfano et al., unpublished observations).

Recent results obtained in our laboratory show that the expression of AMPs of Ae. aegypti mosquitoes is modified with antibiotic treatment and subsequent infection with $P$. gallinaceum. Insects treated with kanamycin had increased expression of defensin $24 \mathrm{~h}$ and $36 \mathrm{~h}$ after being fed an infective blood meal, in comparison with a group of mosquitoes not treated with antibiotics that were fed an infective blood meal. This period in particular occurs when the ookinete begins to invade the intestinal epithelium, reducing infection. Similar results were observed in similar experiments with An. gambiae mosquitoes upon infection with $P$. berghei; a peak of defensin expression was detected at $26 \mathrm{~h}$ after the antibiotic-treated mosquitoes were fed an infective blood meal (Richman et al. 1997). In our model, when the insects are treated with carbenicillin and infected, the expression levels of defensin were inferior to those of the control mosquitoes at $24 \mathrm{~h}$ and $36 \mathrm{~h}$ after blood feeding, revealing a less active immune system, which probably leads to a greater susceptibility to the avian malaria parasite.

In conclusion, we would like to highlight the fact that vector biology has made great advancements over the past years and many results have been attained by "synergic" approaches with computational science as a key element. Many interesting theories are now being discussed and explored regarding the hologenomic basis of speciation (Nikoh et al. 2008, Rosenberg \& ZilberRosenberg 2011, Ni et al. 2012, Brucker \& Bordenstein 2013) and how bacteria and viruses may be shaping the genomes and phenotypes of harbouring organisms (Gorski et al. 2003, Crochu et al. 2004, Degnan \& Moran 2008, Keeling \& Palmer 2008, Nikoh et al. 2008, Klasson et al. 2009, Rohwer et al. 2009, Holmes 2011, Rosario \& Breitbart 2011, Ni et al. 2012, Reyes et al. 2012, Stern et al. 2012, Horie et al. 2013, Husnik et al. 2013, Ioannidis et al. 2013, Seed et al. 2013). When we take into consideration the fact that there are one million bacteria and 10 million viral particles per millilitre of surface seawater (Suttle 2005, Ng et al. 2011b, Rosario \& Breitbart 2011), maximising the NGS sequencing data generated by the An. aquasalis genome project becomes an opportunity to explore many of these new avenues. These vast surroundings and potentially associated microcosms may have left their mark upon the coevolving larval stages of this species while developing in brackish waters.

\section{REFERENCES}

Abraham EG, Jacobs-Lorena M 2004. Mosquito midgut barriers to malaria parasite development. Insect Biochem Mol Biol 34: 667-671.

Ahmed AM, Hurd H 2006. Immune stimulation and malaria infection impose reproductive costs in Anopheles gambiae via follicular apoptosis. Microbes Infect 8: 308-315.

Akaki M, Dvorak JA 2005. A chemotactic response facilitates mosquito salivary gland infection by malaria sporozoites. J Exp Biol 208: 3211-3218.

Alavi Y, Arai M, Mendoza J, Tufet-Bayona M, Sinha R, Fowler K, Billker O, Franke-Fayard B, Janse CJ, Waters A 2003. The dynamics of interactions between Plasmodium and the mosquito: a study of the infectivity of Plasmodium berghei and Plasmodium gallinaceum and their transmission by Anopheles stephensi, Anopheles gambiae and Aedes aegypti. Int J Parasitol 33: 933-943.

Alexandre MA, Ferreira CO, Siqueira AM, Magalhaes BL, Mourão MP, Lacerda MV, Alecrim M 2010. Severe Plasmodium vivax malaria, Brazilian Amazon. Emerg Infect Dis 16: 1611-1614.

Alphey L, Beard CB, Billingsley P, Coetzee M, Crisanti A, Curtis C, Eggleston P, Godfray C, Hemingway J, Jacobs-Lorena M 2002. Malaria control with genetically manipulated insect vectors. Science 298: 119-121. 
Aly AS, Vaughan AM, Kappe SH 2009. Malaria parasite development in the mosquito and infection of the mammalian host. Аnпи Rev Microbiol 63: 195-221.

Amino R, Thiberge S, Martin B, Celli S, Shorte S, Frischknecht F, Menard R 2006. Quantitative imaging of Plasmodium transmission from mosquito to mammal. Nat Med 12: 220-224.

Anderson RJ, Hannan CM, Gilbert SC, Laidlaw SM, Sheu EG, Korten S, Sinden R, Butcher GA, Skinner MA, Hill AV 2004. Enhanced $\mathrm{CD} 8^{+} \mathrm{T}$ cell immune responses and protection elicited against Plasmodium berghei malaria by prime boost immunization regimens using a novel attenuated fowlpox virus. J Immunol 172: 3094-3100

Anduze PJ 1948. Dos variedades nuevas de A. aquasalis. Bol Med 1: 17-19.

Angly FE, Willner D, Prieto-Davo A, Edwards RA, Schmieder R, Vega-Thurber R, Antonopoulos DA, Barott K, Cottrell MT, Desnues C 2009. The GAAS metagenomic tool and its estimations of viral and microbial average genome size in four major biomes. PLoS Comput Biol 5: e1000593.

Ansorge WJ 2009. Next-generation DNA sequencing techniques. $N$ Biotechnol 25: 195-203

Anthony TG, Polley SD, Vogler AP, Conway DJ 2007. Evidence of non-neutral polymorphism in Plasmodium falciparum gamete surface protein genes $P f_{s} 47$ and $P f_{s} 48 / 45$. Mol Biochem Parasitol 156: $117-123$

Arruda ME, Rios RI, Arantes PC, Oliveira AC, Nascimento LP 1982. Manutenção em laboratório de Anopheles albitarsis e Anopheles aquasalis por copulação induzida. Mem Inst Oswaldo Cruz 77: 89-91.

Azambuja P, Garcia ES, Ratcliffe NA 2005. Gut microbiota and parasite transmission by insect vectors. Trends Parasitol 21: 568-572.

Bahia AC, Kubota MS, Tempone AJ, Araújo HR, Guedes BA, Orfano AS, Tadei WP, Ríos-Velasquez CM, Han YS, Secundino NF 2011. The JAK-STAT pathway controls Plasmodium vivax load in early stages of Anopheles aquasalis infection. PLoS Negl Trop Dis 5: e1317.

Bahia AC, Kubota MS, Tempone AJ, Pinheiro WD, Tadei WP, Secundino NF, Traub-Cseko YM, Pimenta PF 2010. Anopheles aquasalis infected by Plasmodium vivax displays unique gene expression profiles when compared to other malaria vectors and plasmodia. PLOS ONE 5: e9795.

Bahia AC, Oliveira JH, Kubota MS, Araújo HR, Lima JB, Ríos-Velasquez CM, Lacerda MV, Oliveira PL, Traub-Cseko YM, Pimenta PF 2013. The role of reactive oxygen species in Anopheles aquasalis response to Plasmodium vivax infection. PLoS ONE 8: e57014.

Baker RH 1964. Mating problems as related to the establishment and maintenance of laboratory colonies of mosquitos. Bull World Health Organ 31: 467-468.

Baker RH, French WL, Kitzmiller JB 1962. Induced copulation in Anopheles mosquitoes. Mosq News 22: 16-17.

Baldacci P, Menard R 2004. The elusive malaria sporozoite in the mammalian host. Mol Microbiol 54: 298-306.

Basset Y, Cizek L, Cuenoud P, Didham RK, Guilhaumon F, Missa O, Novotny V, Odegaard F, Roslin T, Schmidl J 2012. Arthropod diversity in a tropical forest. Science 338: 1481-1484.

Baton LA, Ranford-Cartwright LC 2005. Spreading the seeds of million-murdering death: metamorphoses of malaria in the mosquito. Trends Parasitol 21: 573-580.

Baton LA, Robertson A, Warr E, Strand MR, Dimopoulos G 2009. Genome-wide transcriptomic profiling of Anopheles gambiae hemo- cytes reveals pathogen-specific signatures upon bacterial challenge and Plasmodium berghei infection. BMC Genomics 10: 257.

Baumann P 2005. Biology bacteriocyte-associated endosymbionts of plant sap-sucking insects. Annu Rev Microbiol 59: 155-189.

Beard CB, Dotson EM, Pennington PM, Eichler S, Cordon-Rosales C, Durvasula RV 2001. Bacterial symbiosis and paratransgenic control of vector-borne Chagas disease. Int J Parasitol 31: 621-627.

Benedict MQ, Robinson AS 2003. The first releases of transgenic mosquitoes: an argument for the sterile insect technique. Trends Parasitol 19: 349-355.

Berti J, Zimmerman R, Amarista J 1993. Spatial and temporal distribution of anopheline larvae in two malarious areas in Sucre state, Venezuela. Mem Inst Oswaldo Cruz 88: 353-362.

Besansky NJ 2014. Genome analysis of vectorial capacity in major Anopheles vectors of malaria parasites. Available from: vectorbase.org/index.php/Anopheles_species_cluster_white_ paper\#tab=Details.

Billingsley PF, Sinden RE 1997. Determinants of malaria-mosquito specificity. Parasitol Today 13: 297-301.

Billker O, Lindo V, Panico M, Etienne AE, Paxton T, Dell A, Rogers M, Sinden RE, Morris HR 1998. Identification of xanthurenic acid as the putative inducer of malaria development in the mosquito. Nature 392: 289-292.

Billker O, Shaw MK, Margos G, Sinden RE 1997. The roles of temperature, $\mathrm{pH}$ and mosquito factors as triggers of male and female gametogenesis of Plasmodium berghei in vitro. Parasitology 115: 1-7.

Bishop-Lilly KA, Turell MJ, Willner KM, Butani A, Nolan NM, Lentz SM, Akmal A, Mateczun A, Brahmbhatt TN, Sozhamannan $\mathrm{S}$ 2010. Arbovirus detection in insect vectors by rapid, highthroughput pyrosequencing. PLoS Negl Trop Dis 4: e878.

Blandin S, Shiao SH, Moita LF, Janse CJ, Waters AP, Kafatos FC, Levashina EA 2004. Complement-like protein TEP1 is a determinant of vectorial capacity in the malaria vector Anopheles gambiae. Cell 116: 661-670.

Blandin SA, Levashina EA 2007. Phagocytosis in mosquito immune responses. Immunol Rev 219: 8-16.

Bodner M, Perego UA, Huber G, Fendt L, Rock AW, Zimmermann B, Olivieri A, Gomez-Carballa A, Lancioni H, Angerhofer N 2012. Rapid coastal spread of First Americans: novel insights from South America's Southern Cone mitochondrial genomes. Genome Res 22: 811-820.

Boete C 2005. Malaria parasites in mosquitoes: laboratory models, evolutionary temptation and the real world. Trends Parasitol 21: 445-447.

Boissiere A, Tchioffo MT, Bachar D, Abate L, Marie A, Nsango SE, Shahbazkia HR, Awono-Ambene PH, Levashina EA, Christen R 2012. Midgut microbiota of the malaria mosquito vector Anopheles gambiae and interactions with Plasmodium falciparum infection. PLoS Pathog 8: e1002742.

Boulanger N, Lowenberger C, Volf P, Ursic R, Sigutova L, Sabatier L, Svobodova M, Beverley SM, Spath G, Brun R 2004. Characterization of a defensin from the sand fly Phlebotomus duboscqi induced by challenge with bacteria or the protozoan parasite Leishmania major. Infect Immun 72: 7140-7146.

Boyd MF, Cain TFJ, Mulrennan JA 1935. The insectary rearing of Anopheles quadrimaculatus. Am J Trop Med 15: 384-402.

Branquinho MS, Lagos CB, Rocha RM, Natal D, Barata JM, Cochrane AH, Nardin E, Nussenzweig RS, Kloetzel JK 1993. Anophelines in the state of Acre, Brazil, infected with Plasmodium falciparum, $P$. vivax, the variant $P$. vivax VK247 and $P$. malariae. Trans R Soc Trop Med Hyg 87: 391-394. 
Brucker RM, Bordenstein SR 2013. The capacious hologenome. Zoology (Jena) 116: 260-261.

Buralli GM, Bergo ES 1988. Maintenance of Anopheles darlingi Root, 1926 colony, in the laboratory. Rev Inst Med Trop Sao Paulo 30: 157-164.

Carius HJ, Little TJ, Ebert D 2001. Genetic variation in a host-parasite association: potential for coevolution and frequency-dependent selection. Evolution 55: 1136-1145.

Carpi G, Cagnacci F, Wittekindt NE, Zhao F, Qi J, Tomsho LP, Drautz DI, Rizzoli A, Schuster SC 2011. Metagenomic profile of the bacterial communities associated with Ixodes ricinus ticks. PLoS ONE 6: e25604.

Carter R, Miller LH 1979. Evidence for environmental modulation of gametocytogenesis in Plasmodium falciparum in continuous culture. Bull World Health Organ 57 (Suppl. 1): 37-52.

Carvalho LH, Ferrari WM, Krettli AU 1992. A method for screening drugs against the liver stages of malaria using Plasmodium gallinaceum and Aedes mosquitos. Braz J Med Biol Res 25: 247-255.

Cavasini MT, Ribeiro WL, Kawamoto F, Ferreira MU 2000. How prevalent is Plasmodium malariae in Rondônia, western Brazilian Amazon? Rev Soc Bras Med Trop 33: 489-492.

Chadee DD, Kitron U 1999. Spatial and temporal patterns of imported malaria cases and local transmission in Trinidad. Am J Trop Med Hyg 61: 513-517.

Chadee DD, Le MA, Tilluckdharry CC 1992. An outbreak of Plasmodium vivax malaria in Trinidad, WI. Ann Trop Med Parasitol 86: 583-590.

Chavshin AR, Oshaghi MA, Vatandoost H, Pourmand MR, Raeisi A, Enayati AA, Mardani N, Ghoorchian S 2012. Identification of bacterial microflora in the midgut of the larvae and adult of wild caught Anopheles stephensi: a step toward finding suitable paratransgenesis candidates. Acta Trop 121: 129-134.

Chouaia B, Rossi P, Montagna M, Ricci I, Crotti E, Damiani C, Epis S, Faye I, Sagnon N, Alma A 2010. Molecular evidence for multiple infections as revealed by typing of Asaia bacterial symbionts of four mosquito species. Appl Environ Microbiol 76: 7444-7450.

Christophides GK, Zdobnov E, Barillas-Mury C, Birney E, Blandin S, Blass C, Brey PT, Collins FH, Danielli A, Dimopoulos G 2002. Immunity-related genes and gene families in Anopheles gambiae. Science 298: 159-165.

Cienfuegos AV, Rosero DA, Naranjo N, Luckhart S, Conn JE, Correa MM 2011. Evaluation of a PCR-RFLP-ITS2 assay for discrimination of Anopheles species in northern and western Colombia. Acta Trop 118: 128-135.

Cirimotich CM, Dong Y, Clayton AM, Sandiford SL, Souza-Neto JA, Mulenga M, Dimopoulos G 2011. Natural microbe-mediated refractoriness to Plasmodium infection in Anopheles gambiae. Science 332: 855-858.

Cirimotich CM, Dong Y, Garver LS, Sim S, Dimopoulos G 2010. Mosquito immune defenses against Plasmodium infection. Dev Comp Immunol 34: 387-395.

Clemente JC, Jansson J, Valiente G 2010. Accurate taxonomic assignment of short pyrosequencing reads. Pac Symp Biocomput 2010: 3-9.

Cohuet A, Harris C, Robert V, Fontenille D 2010. Evolutionary forces on Anopheles: what makes a malaria vector? Trends Parasitol 26: 130-136.

Cohuet A, Osta MA, Morlais I, Awono-Ambene PH, Michel K, Simard F, Christophides GK, Fontenille D, Kafatos FC 2006. Anopheles and Plasmodium: from laboratory models to natural systems in the field. EMBO Rep 7: 1285-1289.
Collins FH, Sakai RK, Vernick KD, Paskewitz S, Seeley DC, Miller LH, Collins WE, Campbell CC, Gwadz RW 1986. Genetic selection of a Plasmodium-refractory strain of the malaria vector Anopheles gambiae. Science 234: 607-610.

Conn J, Cockburn AF, Mitchell SE 1993. Population differentiation of the malaria vector Anopheles aquasalis using mitochondrial DNA. J Hered 84: 248-253.

Consoli R, Lourenço-de-Oliveira R 1994. Principais mosquitos de importância sanitária no Brasil, Editora Fiocruz, Rio de Janeiro, $228 \mathrm{pp}$.

Conway DJ, Machado RL, Singh B, Dessert P, Mikes ZS, Póvoa MM, Oduola AM, Roper C 2001. Extreme geographical fixation of variation in the Plasmodium falciparum gamete surface protein gene $P f_{S} 48 / 45$ compared with microsatellite loci. Mol Biochem Parasitol 115: 145-156.

Corrêa RR, Ferreira E, Ramalho GR, Zaia L 1970. Informe sobre uma colônia de Anopheles darlingi. Proceedings of the XVIII Congresso Brasileiro de Higiene, 1970 October 6-31, São Paulo, Brasil, Sociedade Brasileira de Higiene, Rio de Janeiro, p. 80.

Costa FT, Lopes SC, Albrecht L, Ataide R, Siqueira AM, Souza RM, Russell B, Renia L, Marinho CR, Lacerda MV 2012. On the pathogenesis of Plasmodium vivax malaria: perspectives from the Brazilian field. Int J Parasitol 42: 1099-1105.

Crochu S, Cook S, Attoui H, Charrel RN, de Chesse R, Belhouchet M, Lemasson JJ, de Micco P, de Lamballerie X 2004. Sequences of flavivirus-related RNA viruses persist in DNA form integrated in the genome of Aedes spp mosquitoes. J Gen Virol 85: 1971-1980.

Cruz LR, Spangenberg T, Lacerda MV, Wells TN 2013. Malaria in South America: a drug discovery perspective. Malar J 12: 168.

Curry DP 1932. Some observation on the Nyssorhynchus group of the Anopheles (Culicidae) of Panama. Am J Epidemiol 15: 566-572.

da Ramos AS 1942. Sobre uma variedade nova de Anopheles (Nysoorhynchus) oswaldoi Peryassú, 1922 (Diptera-Culicidae). Arq Hig Saude Publica 7: 61-71.

da Rocha ACVM, Braga EM, Araújo MSS, Franklin BS, Pimenta PFP 2004. Effect of the Aedes fluviatilis saliva on the development of Plasmodium gallinaceum infection in Gallus (gallus) domesticus. Mem Inst Oswaldo Cruz 99: 709-715.

da Rocha JA, de Oliveira SB, Póvoa MM, Moreira LA, Krettli AU 2008. Malaria vectors in areas of Plasmodium falciparum epidemic transmission in the Amazon Region, Brazil. Am J Trop Med Hyg 78: 872-877.

da Silva AN, dos Santos CC, Lacerda RN, Rosa EPS, de Souza RT, Galiza D, Sucupira I, Conn JE, Póvoa MM 2006a. Laboratory colonization of Anopheles aquasalis (Diptera: Culicidae) in Belém, Pará, Brazil. J Med Entomol 43: 107-109.

da Silva ANM, Santos CCB, Lacerda RN, Machado RLD, Póvoa MM 2006b. Susceptibility of Anopheles aquasalis and An. darlingi to Plasmodium vivax VK210 and VK247. Mem Inst Oswaldo Cruz 101: $547-550$

da Silva-Vasconcelos A, Kató MYN, Mourão EN, de Souza RTL, Lacerda RNL, Sibajev A, Tsouris P, Póvoa MM, Momen H, RosaFreitas MG 2002. Biting indices, host-seeking activity and natural infection rates of anopheline species in Boa Vista, Roraima, Brazil from 1996 to 1998. Mem Inst Oswaldo Cruz 97: 151-161.

Dana AN, Hong YS, Kern MK, Hillenmeyer ME, Harker BW, Lobo NF, Hogan JR, Romans P, Collins FH 2005. Gene expression patterns associated with blood-feeding in the malaria mosquito Anopheles gambiae. BMC Genomics 6: 5 .

de Arruda M, Carvalho MB, Nussenzweig RS, Maracic M, Ferreira AW, Cochrane AH 1986. Potential vectors of malaria and their 
different susceptibility to Plasmodium falciparum and Plasmodium vivax in northern Brazil identified by immunoassay. Am J Trop Med Hyg 35: 873-881.

de Camargo MVT, Cônsoli RAGB, Williams P, Krettli AU 1983. Factors influencing the development of Plasmodium gallinaceum in Aedes fluviatilis. Mem Inst Oswaldo Cruz 78: 83-94.

de Oliveira-Ferreira J, Lourenço-de-Oliveira R, Teva A, Deane LM, Daniel-Ribeiro CT 1990. Natural malaria infections in anophelines in Rondônia state, Brazilian Amazon. Am J Trop Med Hyg 43: 6-10.

Deane LM 1986. Malaria vectors in Brazil. Mem Inst Oswaldo Cruz 81 (Suppl. II): 5-14.

Deane LM, Causey OR, Deane MP 1948. Notas sôbre a distribuição e a biologia dosanofelinos das regiões nordestina e amazônica do Brasil. R Serv Espec Saú Púb 1: 827-965.

Degnan PH, Moran NA 2008. Diverse phage-encoded toxins in a protective insect endosymbiont. Appl Environ Microbiol 74: 6782-6791.

Delcher AL, Bratke KA, Powers EC, Salzberg SL 2007. Identifying bacterial genes and endosymbiont DNA with Glimmer. Bioinformatics 23: 673-679.

Dessens JT, Beetsma AL, Dimopoulos G, Wengelnik K, Crisanti A, Kafatos FC, Sinden RE 1999. CTRP is essential for mosquito infection by malaria ookinetes. EMBO J 18: 6221-6227.

Dillon RJ, Dillon VM 2004. The gut bacteria of insects: nonpathogenic interactions. Annu Rev Entomol 49: 71-92.

Dimopoulos G, Christophides GK, Meister S, Schultz J, White KP, Barillas-Mury C, Kafatos FC 2002. Genome expression analysis of Anopheles gambiae: responses to injury, bacterial challenge and malaria infection. Proc Natl Acad Sci USA 99: 8814-8819.

Dimopoulos G, Muller HM, Levashina EA, Kafatos FC 2001. Innate immune defense against malaria infection in the mosquito. Curr Opin Immunol 13: 79-88.

Dinglasan RR, Devenport M, Florens L, Johnson JR, McHugh CA, Donnelly-Doman M, Carucci DJ, Yates JR III, Jacobs-Lorena M 2009. The Anopheles gambiae adult midgut peritrophic matrix proteome. Insect Biochem Mol Biol 39: 125-134.

Dinparast DN, Jazayeri H, Raz A, Favia G, Ricci I, Zakeri S 2011. Identification of the midgut microbiota of An. stephensi and An. maculipennis for their application as a paratransgenic tool against malaria. PLoS ONE 6: e28484.

Dong Y, Aguilar R, Xi Z, Warr E, Mongin E, Dimopoulos G 2006. Anopheles gambiae immune responses to human and rodent Plasmodium parasite species. PLoS Pathog 2: e52.

Dong Y, Manfredini F, Dimopoulos G 2009. Implication of the mosquito midgut microbiota in the defense against malaria parasites. PLoS Pathog 5: e1000423.

dos Santos RL, Sucupira IM, Lacerda RN, Fayal AS, Póvoa MM 2005. Entomological survey and infectivity during malaria outbreak in the Anajás municipality, Pará state. Rev Soc Bras Med Trop 38: 202-204.

Duarte AM, Pereira DM, de Paula MB, Fernandes A, Urbinatti PR, Ribeiro AF, Mello MH, Matos Jr MO, Mucci LF, Fernandes LN 2013. Natural infection in anopheline species and its implications for autochthonous malaria in the Atlantic Forest in Brazil. Parasit Vectors 6: 58.

Eappen AG, Smith RC, Jacobs-Lorena M 2013. Enterobacter-activated mosquito immune responses to Plasmodium involve activation of SRPN6 in Anopheles stephensi. PLoS ONE 8: e62937.

Engel P, Moran NA 2013. The gut microbiota of insects - diversity in structure and function. FEMS Microbiol Rev 37: 699-735.
Fagundes NJ, Kanitz R, Eckert R, Valls AC, Bogo MR, Salzano FM, Smith DG, Silva Jr WA, Zago MA, Ribeiro-dos-Santos AK 2008. Mitochondrial population genomics supports a single pre-Clovis origin with a coastal route for the peopling of the Americas. Am J Hum Genet 82: 583-592.

Fairley TL, Kilpatrick CW, Conn JE 2005. Intragenomic heterogeneity of internal transcribed spacer rDNA in neotropical malaria vector Anopheles aquasalis (Diptera: Culicidae). J Med Entomol 42: 795-800.

Fairley TL, Póvoa MM, Conn JE 2002. Evaluation of the Amazon River delta as a barrier to gene flow for the regional malaria vector, Anopheles aquasalis (Diptera: Culicidae) in northeastern Brazil. J Med Entomol 39: 861-869.

Faran ME 1980. Mosquito studies (Diptera, Culicidae) XXXIV. A revision of the Albimanus section of the subgenus Nyssorhynchus of Anopheles. Contrib Amer Ent Inst 15: 1-216.

Favia G, Ricci I, Damiani C, Raddadi N, Crotti E, Marzorati M, Rizzi A, Urso R, Brusetti L, Borin S 2007. Bacteria of the genus Asaia stably associate with Anopheles stephensi, an Asian malarial mosquito vector. Proc Natl Acad Sci USA 104: 9047-9051.

Field D, Garrity GM, Sansone SA, Sterk P, Gray T, Kyrpides N, Hirschman L, Glockner FO, Kottmann R, Angiuoli S 2008. Meeting report: the fifth Genomic Standards Consortium (GSC) workshop. OMICS 12: 109-113.

Flores-Mendoza C, Cunha RA, Rocha DS, Lourenço-de-Oliveira R 1996. Identification of food sources of Anopheles aquasalis (Diptera: Culicidae) by precipitin test in the state of Rio de Janeiro, Brazil. Rev Saude Publica 30: 129-134.

Foley DH, Linton YM, Ruiz-Lopez JF, Conn JE, Sallum MA, Póvoa MM, Bergo ES, Oliveira TM, Sucupira I, Wilkerson RC 2014. Geographic distribution, evolution and disease importance of species within the Neotropical Anopheles albitarsis group (Diptera, Culicidae). J Vector Ecol 39: 168-181.

Franke-Fayard B, Trueman H, Ramesar J, Mendoza J, van der Keur M, van der Linden R, Sinden RE, Waters AP, Janse CJ 2004. A Plasmodium berghei reference line that constitutively expresses GFP at a high level throughout the complete life cycle. Mol Biochem Parasitol 137: 23-33.

Frischknecht F, Martin B, Thiery I, Bourgouin C, Menard R 2006. Using green fluorescent malaria parasites to screen for permissive vector mosquitoes. Malar J 5: 23.

Frolet C, Thoma M, Blandin S, Hoffmann JA, Levashina EA 2006. Boosting NF-kappaB-dependent basal immunity of Anopheles gambiae aborts development of Plasmodium berghei. Immunity 25: 677-685.

Gaio AO, Gusmão DS, Santos AV, Berbert-Molina MA, Pimenta PF, Lemos FJ 2011. Contribution of midgut bacteria to blood digestion and egg production in Aedes aegypti (Diptera: Culicidae) (L.). Parasit Vectors 4: 105.

Galardo AK, Arruda M, Couto AAD, Wirtz R, Lounibos LP, Zimmerman RH 2007. Malaria vector incrimination in three rural riverine villages in the Brazilian Amazon. Am J Trop Med Hyg 76: 461-469.

Galvão ALA, Correa RR, Grieco SJ 1944. Alguns dados sobre a manutenção de colônias de Nyssorhinchus em laboratório. Arq Hig Saude Publica 9: 102-185.

Galvão ALA, Damasceno R, Marques A 1942. Algumas observações sobre a biologia dos anofelinos de importância epidemiológica em Belém do Pará. Arq Hig Saude Publica 12: 51-110.

Garcia PC, Pulido FJ, Amarista JRM 1977. Anophele (Nyssorhynchus) deltaorinoquensis $\mathrm{n}$. sp. (Diptera, Culicidae) de Venezuela. Bol Inf Dir Malariol 17: 150-161. 
Gardner MJ, Hall N, Fung E, White O, Berriman M, Hyman RW, Carlton JM, Pain A, Nelson KE, Bowman S 2002. Genome sequence of the human malaria parasite Plasmodium falciparum. Nature 419: 498-511.

Garver LS, Dong Y, Dimopoulos G 2009. Caspar controls resistance to Plasmodium falciparum in diverse anopheline species. PLoS Pathog 5: e1000335.

Gass RF, Yeates RA 1979. In vitro damage of cultured ookinetes of Plasmodium gallinaceum by digestive proteinases from susceptible Aedes aegypti. Acta Trop 36: 243-252.

Gendrin M, Christophides GK 2013. The Anopheles mosquito microbiota and their impact on pathogen transmission, Anopheles mosquitoes - New insights into malaria vectors. Available from: intechopen.com/books/anopheles-mosquitoes-new-insightsinto-malaria-vectors/the-anopheles-mosquito-microbiota-andtheir-impact-on-pathogen-transmission.

Gerlach W, Stoye J 2011. Taxonomic classification of metagenomic shotgun sequences with CARMA3. Nucleic Acids Res 39: e91.

Ghosh A, Edwards MJ, Jacobs-Lorena M 2000. The journey of the malaria parasite in the mosquito: hopes for the new century. $P a$ rasitol Today 16: 196-201.

Giglioli G 1963. Ecological change as a factor in renewed malaria transmission in an eradicated area. A localized outbreak of $A$. aquasalis-transmitted malaria on the Demerara River estuary, British Guiana, in the fifteenth year of $A$. darling $i$ and malaria eradication. Bull World Health Organ 29: 131-145.

Glass EM, Wilkening J, Wilke A, Antonopoulos D, Meyer F 2010. Using the metagenomics RAST server (MG-RAST) for analyzing shotgun metagenomes. Cold Spring Harb Protoc 2010: doi: 10.1101/pdb.prot5368.

Gonçalves RL, Oliveira JH, Oliveira GA, Andersen JF, Oliveira MF, Oliveira PL, Barillas-Mury C 2012. Mitochondrial reactive oxygen species modulate mosquito susceptibility to Plasmodium infection. PLoS ONE 7: e41083.

González-Cerón L, Santillan F, Rodríguez MH, Mendez D, Hernández-Ávila JE 2003. Bacteria in midguts of field-collected Anopheles albimanus block Plasmodium vivax sporogonic development. J Med Entomol 40: 371-374.

Gorski A, Dabrowska K, Switala-Jelen K, Nowaczyk M, WeberDabrowska B, Boratynski J, Wietrzyk J, Opolski A 2003. New insights into the possible role of bacteriophages in host defense and disease. Med Immunol 2: 2 .

Gouagna LC, Yao F, Yameogo B, Dabire RK, Ouedraogo JB 2013. Comparison of field-based xenodiagnosis and direct membrane feeding assays for evaluating host infectiousness to malaria vector Anopheles gambiae. Acta Trop 130C: 131-139.

Grillet ME 2000. Factors associated with distribution of Anopheles aquasalis and Anopheles oswaldoi (Diptera: Culicidae) in a malarious area, northeastern Venezuela. J Med Entomol 37: 231-238.

Gulley MM, Zhang X, Michel K 2013. The roles of serpins in mosquito immunology and physiology. J Insect Physiol 59: 138-147.

Gupta L, Kumar S, Han YS, Pimenta PF, Barillas-Mury C 2005. Midgut epithelial responses of different mosquito-Plasmodium combinations: the actin cone zipper repair mechanism in Aedes aegypti. Proc Natl Acad Sci USA 102: 4010-4015.

Gupta L, Molina-Cruz A, Kumar S, Rodrigues J, Dixit R, Zamora RE, Barillas-Mury C 2009. The STAT pathway mediates latephase immunity against Plasmodium in the mosquito Anopheles gambiae. Cell Host Microbe 5: 498-507.

Han YS, Thompson J, Kafatos FC, Barillas-Mury C 2000. Molecular interactions between Anopheles stephensi midgut cells and Plas- modium berghei: the time bomb theory of ookinete invasion of mosquitoes. EMBO J 19: 6030-6040.

Harris C, Lambrechts L, Rousset F, Abate L, Nsango SE, Fontenille D, Morlais I, Cohuet A 2010. Polymorphisms in Anopheles gambiae immune genes associated with natural resistance to Plasmodium falciparum. PLoS Pathog 6: e1001112.

Harris C, Morlais I, Churcher TS, Awono-Ambene P, Gouagna LC, Dabire RK, Fontenille D, Cohuet A 2012. Plasmodium falciparum produce lower infection intensities in local versus foreign Anopheles gambiae populations. PLoS ONE 7: e30849.

Herrera S, Solarte Y, Jordan-Villegas A, Echavarria JF, Rocha L, Palacios R, Ramirez O, Velez JD, Epstein JE, Richie TL 2011. Consistent safety and infectivity in sporozoite challenge model of Plasmodium vivax in malaria-naïve human volunteers. Am J Trop Med Hyg 84: 4-11.

Herrera-Ortiz A, Martinez-Barnetche J, Smit N, Rodriguez MH, Lanz-Mendoza H 2011. The effect of nitric oxide and hydrogen peroxide in the activation of the systemic immune response of Anopheles albimanus infected with Plasmodium berghei. Dev Comp Immunol 35: 44-50.

Hillyer JF, Barreau C, Vernick KD 2007. Efficiency of salivary gland invasion by malaria sporozoites is controlled by rapid sporozoite destruction in the mosquito haemocoel. Int J Parasitol 37: 673-681.

Hillyer JF, Schmidt SL, Christensen BM 2003. Rapid phagocytosis and melanization of bacteria and Plasmodium sporozoites by hemocytes of the mosquito Aedes aegypti. J Parasitol 89: 62-69.

Hiwat H, Issaly J, Gaborit P, Somai A, Samjhawan A, Sardjoe P, Soekhoe T, Girod R 2010. Behavioral heterogeneity of Anopheles darlingi (Diptera: Culicidae) and malaria transmission dynamics along the Maroni River, Suriname, French Guiana. Trans $R$ Soc Trop Med Hyg 104: 207-213.

Hoffmann JA, Kafatos FC, Janeway CA, Ezekowitz RA 1999. Phylogenetic perspectives in innate immunity. Science 284: 1313-1318.

Holmes EC 2011. The evolution of endogenous viral elements. Cell Host Microbe 10: 368-377.

Holt RA, Subramanian GM, Halpern A, Sutton GG, Charlab R, Nusskern DR, Wincker P, Clark AG, Ribeiro JM, Wides R 2002. The genome sequence of the malaria mosquito Anopheles gambiae. Science 298: 129-149.

Hopwood JA, Ahmed AM, Polwart A, Williams GT, Hurd H 2001. Malaria-induced apoptosis in mosquito ovaries: a mechanism to control vector egg production. J Exp Biol 204: 2773-2780.

Horie M, Kobayashi Y, Suzuki Y, Tomonaga K 2013. Comprehensive analysis of endogenous bornavirus-like elements in eukaryote genomes. Philos Trans R Soc Lond B Biol Sci 368: 20120499.

Horosko III S, Lima JBP, Brandolini MB 1997. Establishment of a free-mating colony of Anopheles albitarsis from Brazil. $J$ Am Mosq Control Assoc 13: 95-96.

Hubbe M, Neves WA, Harvati K 2010. Testing evolutionary and dispersion scenarios for the settlement of the New World. PLOS ONE 5: e11105.

Huber M, Cabib E, Miller LH 1991. Malaria parasite chitinase and penetration of the mosquito peritrophic membrane. Proc Natl Acad Sci USA 88: 2807-2810.

Hume JC, Tunnicliff M, Ranford-Cartwright LC, Day KP 2007. Susceptibility of Anopheles gambiae and Anopheles stephensi to tropical isolates of Plasmodium falciparum. Malar J 6: 139.

Husnik F, Nikoh N, Koga R, Ross L, Duncan RP, Fujie M, Tanaka M, Satoh N, Bachtrog D, Wilson AC 2013. Horizontal gene transfer from diverse bacteria to an insect genome enables a tripartite nested mealybug symbiosis. Cell 153: 1567-1578. 
Huson DH, Auch AF, Qi J, Schuster SC 2007. MEGAN analysis of metagenomic data. Genome Res 17: 377-386.

Huttenhower EA 2012. Structure, function and diversity of the healthy human microbiome. Nature 486: 207-214.

Ioannidis P, Johnston KL, Riley DR, Kumar N, White JR, Olarte KT, Ott S, Tallon LJ, Foster JM, Taylor MJ 2013. Extensively duplicated and transcriptionally active recent lateral gene transfer from a bacterial Wolbachia endosymbiont to its host filarial nematode Brugia malayi. BMC Genomics 14: 639.

Isaacs AT, Li F, Jasinskiene N, Chen X, Nirmala X, Marinotti O, Vinetz JM, James AA 2011. Engineered resistance to Plasmodium falciparum development in transgenic Anopheles stephensi. PLoS Pathog 7: e1002017.

Ishino T, Yano K, Chinzei Y, Yuda M 2004. Cell-passage activity is required for the malarial parasite to cross the liver sinusoidal cell layer. PLoS Biol 2: E4.

Jahan N, Docherty PT, Billingsley PF, Hurd H 1999. Blood digestion in the mosquito, Anopheles stephensi: the effects of Plasmodium yoelii nigeriensis on midgut enzyme activities. Parasitology 119: 535-541.

Jambou R, Martinelli A, Pinto J, Gribaldo S, Legrand E, Niang M, Kim N, Pharath L, Volnay B, Ekala MT 2010. Geographic structuring of the Plasmodium falciparum sarco(endo)plasmic reticulum Ca2+ ATPase (PfSERCA) gene diversity. PLoS ONE 5: e9424.

Jaramillo-Gutierrez G, Rodrigues J, Ndikuyeze G, Povelones M, Molina-Cruz A, Barillas-Mury C 2009. Mosquito immune responses and compatibility between Plasmodium parasites and anopheline mosquitoes. BMC Microbiol 9: 154.

Jiang H, An L, Lin SM, Feng G, Qiu Y 2012. A statistical framework for accurate taxonomic assignment of metagenomic sequencing reads. PLOS ONE 7: e46450.

Keeling PJ, Palmer JD 2008. Horizontal gene transfer in eukaryotic evolution. Nat Rev Genet 9: 605-618.

Killick-Kendrick R 1978. Taxonomy, zoography and evolution. In R Killick-Kendrick, W Peters (eds.), Rodents malaria, Academic Press, London, p. 1-52.

Kim M, Lee KH, Yoon SW, Kim BS, Chun J, Yi H 2013. Analytical tools and databases for metagenomics in the next-generation sequencing era. Genomics Inform 11: 102-113.

Klasson L, Kambris Z, Cook PE, Walker T, Sinkins SP 2009. Horizontal gene transfer between Wolbachia and the mosquito Aedes aegypti. BMC Genomics 10: 33.

Klein TA, Lima JB, Tada MS 1991a. Comparative susceptibility of anopheline mosquitoes to Plasmodium falciparum in Rondônia, Brazil. Am J Trop Med Hyg 44: 598-603.

Klein TA, Lima JB, Tada MS, Miller R 1991b. Comparative susceptibility of anopheline mosquitoes in Rondônia, Brazil to infection by Plasmodium vivax. Am J Trop Med Hyg 45: 463-470.

Klein TA, Lima JB, Toda-Tang A 1990. Colonization and maintenance of Anopheles deaneorum in Brazil. J Am Mosq Control Assoc 6: 510-513.

Klein TA, Tada MS, Lima JB, Katsuragawa TH 1991c. Infection of Anopheles darlingi fed on patients infected with Plasmodium vivax before and during treatment with chloroquine in Costa Marques, Rondônia, Brazil. Am J Trop Med Hyg 45: 471-478.

Komp WH 1941. The species of Nyssorhynchus confused under tarsimaculatus Goeldi and a new name A. emilianus, for one species found in Pará, Brazil (Diptera, Culicidae). Ann Entomol Soc Am 34: 791-807.

Korochkina S, Barreau C, Pradel G, Jeffery E, Li J, Natarajan R, Shabanowitz J, Hunt D, Frevert U, Vernick KD 2006. A mosquito- specific protein family includes candidate receptors for malaria sporozoite invasion of salivary glands. Cell Microbiol 8: 163-175.

Krettli AU, Andrade-Neto VF, Brandão MGL, Ferrari WMS 2001. The search for new antimalarial drugs from plants used to treat fever and malaria or plants ramdomly selected: a Review. Mem Inst Oswaldo Cruz 96: 1033-1042.

Kumar S, Christophides GK, Cantera R, Charles B, Han YS, Meister S, Dimopoulos G, Kafatos FC, Barillas-Mury C 2003. The role of reactive oxygen species on Plasmodium melanotic encapsulation in Anopheles gambiae. Proc Natl Acad Sci USA 100: 14139-14144.

Kumar S, Molina-Cruz A, Gupta L, Rodrigues J, Barillas-Mury C 2010. A peroxidase/dual oxidase system modulates midgut epithelial immunity in Anopheles gambiae. Science 327: 1644-1648.

Lacerda MV, Mourão MP, Alexandre MA, Siqueira AM, Magalhães BM, Martinez-Espinosa FE, Filho FS, Brasil P, Ventura AM, Tada MS 2012. Understanding the clinical spectrum of complicated Plasmodium vivax malaria: a systematic review on the contributions of the Brazilian literature. Malar J 11: 12.

Lambrechts L, Halbert J, Durand P, Gouagna LC, Koella JC 2005. Host genotype by parasite genotype interactions underlying the resistance of anopheline mosquitoes to Plasmodium falciparum. Malar J 4: 3 .

Lambrechts L, Morlais I, Awono-Ambene PH, Cohuet A, Simard F, Jacques JC, Bourgouin C, Koella JC 2007. Effect of infection by Plasmodium falciparum on the melanization immune response of Anopheles gambiae. Am J Trop Med Hyg 76: 475-480.

Lardeux F, Quispe V, Tejerina R, Rodriguez R, Torrez L, Bouchite B, Chavez T 2007. Laboratory colonization of Anopheles pseudopunctipennis (Diptera: Culicidae) without forced mating. $C R$ Biol 330: 571-575.

Laubach HE, Validum L, Bonilla JA, Agar A, Cummings R, Mitchell C, Cuadrado RR, Palmer CJ 2001. Identification of Anopheles aquasalis as a possible vector of malaria in Guyana, South America. West Indian Med J 50: 319-321.

Levashina EA 2004. Immune responses in Anopheles gambiae. Insect Biochem Mol Biol 34: 673-678.

Levashina EA, Moita LF, Blandin S, Vriend G, Lagueux M, Kafatos FC 2001. Conserved role of a complement-like protein in phagocytosis revealed by dsRNA knockout in cultured cells of the mosquito, Anopheles gambiae. Cell 104: 709-718.

Li J, Riehle MM, Zhang Y, Xu J, Oduol F, Gomez SM, Eiglmeier K, Ueberheide BM, Shabanowitz J, Hunt DF 2006. Anopheles gambiae genome reannotation through synthesis of ab initio and comparative gene prediction algorithms. Genome Biol 7: R24.

Li R, Fan W, Tian G, Zhu H, He L, Cai J, Huang Q, Cai Q, Li B, Bai Y 2010. The sequence and de novo assembly of the giant panda genome. Nature 463: 311-317.

Ligoxygakis P, Pelte N, Hoffmann JA, Reichhart JM 2002. Activation of Drosophila Toll during fungal infection by a blood serine protease. Science 297: 114-116.

Lima JB, Valle D, Peixoto AA 2004. Adaptation of a South American malaria vector to laboratory colonization suggests faster-male evolution for mating ability. BMC Evol Biol 4: 12.

Lindh JM, Lehane MJ 2011. The tsetse fly Glossina fuscipes fuscipes (Diptera: Glossina) harbours a surprising diversity of bacteria other than symbionts. Antonie Van Leeuwenhoek 99: 711-720.

Lindh JM, Terenius O, Faye I 2005. 16S rRNA gene-based identification of midgut bacteria from field-caught Anopheles gambiae sensu lato and $A$. funestus mosquitoes reveals new species related to known insect symbionts. Appl Environ Microbiol 71: 7217-7223.

Linley JR, Lounibos LP, Conn J 1993. A description and morphometric analysis of eggs of four South American populations of 
Anopheles (Nyssorhynchus) aquasalis (Diptera: Culicidae). J Am Mosq Control Assoc 25: 198-214.

Lo TM, Coetzee M 2013. Marked biological differences between insecticide resistant and susceptible strains of Anopheles funestus infected with the murine parasite Plasmodium berghei. Parasit Vectors 6: 184.

Luckhart S, Vodovotz Y, Cui L, Rosenberg R 1998. The mosquito Anopheles stephensi limits malaria parasite development with inducible synthesis of nitric oxide. Proc Natl Acad Sci USA 95: 5700-5705.

Lycett GJ, Kafatos FC 2002. Anti-malarial mosquitoes? Nature 417: 387-388.

Ma X-j, Shu YL, Nie K, Qin M, Wang DY, Gao RB, Wang M, Wen LY, Han F, Zhou SM 2010. Visual detection of pandemic influenza AH1N1 virus 2009 by reverse-transcription loop-mediated isothermal amplification with hydroxynaphthol blue dye. $J$ Virol Methods 167: 214-217.

Maciel C, de Oliveira Jr VX, Fazio MA, Nacif-Pimenta R, Miranda A, Pimenta PF, Capurro ML 2008. Anti-plasmodium activity of angiotensin II and related synthetic peptides. PLoS ONE 3: e3296.

Maldonado V, Finol HJ, Navarro JC 1997. Anopheles aquasalis eggs from two Venezuelan localities compared by scanning electron microscopy. Mem Inst Oswaldo Cruz 92: 487-491.

Manguin S, Peyton EL, James AC, Roberts DR 1993. Apparent changes in the abundance and distribution of Anopheles species on Grenada Island. J Am Mosq Control Assoc 9: 403-407.

Mardis ER 2011. A decade's perspective on DNA sequencing technology. Nature 470: 198-203.

Marinotti O, Cerqueira GC, de Almeida LGP, Ferro MIT, Loreto ELS, Zaha A, Teixeira SMR, Wespiser AR, Silva AA, Schlindwein AD, Pacheco ACL, da Silva ALC, Graveley BR, Walenz BP, Lima BA, Ribeiro CAG, Nunes-Silva CG, de Carvalho CR, Soares CMA, de Menezes CBA, Matiolli C, Caffrey D, Araújo DAM, de Oliveira DM, Golenbock D, Grisard EC, FantinattiGarboggini F, de Carvalho FM, Barcellos FG, Prosdocimi F, May G, de Azevedo Jr GM, Guimarães GM, Goldman GH, Padilha IQM, Batista JS, Ferro JA, Ribeiro JMC, Fietto JLR, Dabbas KM, Cerdeira L, Agnez-Lima LF, Brocchi M, de Carvalho MO, Teixeira MM, Maia MMD, Goldman MHS, Schneider MPC, Felipe MSS, Hungria M, Nicolás MF, Pereira M, Montes MA, Cantão ME, Vincentz M, Rafael MS, Silverman N, Stoco PH, Souza RC, Vicentini R, Gazzinelli RT, Neves RO, Silva R, Astolfi-Filho S, Maciel TEF, Ürményi TP, Tadei WP, Camargo EP, de Vasconcelos ATR 2013. The genome of Anopheles darlingi, the main Neotropical malaria vector. Nucleic Acids Res 41: 7387-7400.

Marrelli MT, Floeter-Winter LM, Malafronte RS, Tadei WP, Lourenço-de-Oliveira R, Flores-Mendoza C, Marinotti O 2005. Amazonian malaria vector anopheline relationships interpreted from ITS2 rDNA sequences. Med Vet Entomol 19: 208-218.

Martinez-Palacios A, Davidson G 1967. The mode of inheritance of dieldrin-resistance in Anopheles (A.) pseudopunctipennis and the crossing of populations of this species from various parts of Mexico. Mosq News 27: 55-56.

McCutchan TF, Kissinger JC, Touray MG, Rogers MJ, Li J, Sullivan M, Braga EM, Krettli AU, Miller LH 1996. Comparison of circumsporozoite proteins from avian and mammalian malarias: biological and phylogenetic implications. Proc Natl Acad Sci USA 93: 11889-11894.

McDaniel IN, Horsfall WR 1957. Induced copulation of aedine mosquitoes. Science 125: 745-750.

Medica DL, Sinnis P 2005. Quantitative dynamics of Plasmodium yoelii sporozoite transmission by infected anopheline mosquitoes. Infect Immun 73: 4363-4369.
Megy K, Emrich SJ, Lawson D, Campbell D, Dialynas E, Hughes DS, Koscielny G, Louis C, Maccallum RM, Redmond SN 2012. VectorBase: improvements to a bioinformatics resource for invertebrate vector genomics. Nucleic Acids Res 40: D729-D734.

Meister S, Agianian B, Turlure F, Relogio A, Morlais I, Kafatos FC, Christophides GK 2009. Anopheles gambiae PGRPLC-mediated defense against bacteria modulates infections with malaria parasites. PLoS Pathog 5: e1000542.

Meister S, Kanzok SM, Zheng XL, Luna C, Li TR, Hoa NT, Clayton JR, White KP, Kafatos FC, Christophides GK 2005. Immune signaling pathways regulating bacterial and malaria parasite infection of the mosquito Anopheles gambiae. Proc Natl Acad Sci USA 102: 11420-11425.

Meyer F, Paarmann D, D’Souza M, Olson R, Glass EM, Kubal M, Paczian T, Rodriguez A, Stevens R, Wilke A 2008. The metagenomics RAST server - a public resource for the automatic phylogenetic and functional analysis of metagenomes. BMC Bioinformatics 9: 386.

Michel K, Budd A, Pinto S, Gibson TJ, Kafatos FC 2005. Anopheles gambiae SRPN2 facilitates midgut invasion by the malaria parasite Plasmodium berghei. EMBO Rep 6: 891-897.

Michel K, Kafatos FC 2005. Mosquito immunity against Plasmodium. Insect Biochem Mol Biol 35: 677-689.

Minard G, Mavingui P, Moro CV 2013. Diversity and function of bacterial microbiota in the mosquito holobiont. Parasit Vectors 6: 146.

Mokili JL, Rohwer F, Dutilh BE 2012. Metagenomics and future perspectives in virus discovery. Curr Opin Virol 2: 63-77.

Molina-Cruz A, Dejong RJ, Charles B, Gupta L, Kumar S, JaramilloGutierrez G, Barillas-Mury C 2008. Reactive oxygen species modulate Anopheles gambiae immunity against bacteria and Plasmodium. J Biol Chem 283: 3217-3223.

Molina-Cruz A, Dejong RJ, Ortega C, Haile A, Abban E, Rodrigues J, Jaramillo-Gutierrez G, Barillas-Mury C 2012. Some strains of Plasmodium falciparum, a human malaria parasite, evade the complement-like system of Anopheles gambiae mosquitoes. Proc Natl Acad Sci USA 109: E1957-E1962.

Molina-Cruz A, Garver LS, Alabaster A, Bangiolo L, Haile A, Winikor J, Ortega C, van Schaijk BC, Sauerwein RW, Taylor-Salmon E 2013. The human malaria parasite $P f_{S} 47$ gene mediates evasion of the mosquito immune system. Science 340: 984-987.

Moon AE, Walker AJ, Goodbourn S 2011. Regulation of transcription of the Aedes albopictus cecropin A1 gene: a role for p38 mitogenactivated protein kinase. Insect Biochem Mol Biol 41: 628-636.

Moores H 1953. A method for maintaining a colony of Anopheles gambiae in the laboratory. Trans R Soc Trop Med Hyg 47: 321-323.

Moreno M, Marinotti O, Krzywinski J, Tadei WP, James AA, Achee NL, Conn JE 2010. Complete mtDNA genomes of Anopheles darlingi and an approach to anopheline divergence time. Malar J 9: 127.

Moreno M, Tong C, Guzman M, Chuquiyauri R, Llanos-Cuentas A, Rodriguez H, Gamboa D, Meister S, Winzeler EA, Maguina P 2014. Infection of laboratory-colonized Anopheles darlingi mosquitoes by Plasmodium vivax. Am J Trop Med Hyg 90: 612-616.

Mouchet J, Carnevale P, Manguin S 2008. Biodiversity of malaria in the world, John Libbey Eurotext, Montrouge, 428 pp.

MS/SVS - Ministério da Saúde/Secretaria de Vigilância em Saúde 2013 Brasil. Situação epidemiológica da malária no Brasil, 2000 a 2011. Bol Epidemiol 44: 1-16.

Nartey R, Owusu-Dabo E, Kruppa T, Baffour-Awuah S, Annan A, Oppong S, Becker N, Obiri-Danso K 2013. Use of Bacillus thuringiensis var. israelensis as a viable option in an Integrated 
Malaria Vector Control Programme in the Kumasi Metropolis, Ghana. Parasit Vectors 6: 116.

Neafsey DE, Christophides GK, Collins FH, Emrich SJ, Fontaine MC, Gelbart W, Hahn MW, Howell PI, Kafatos FC, Lawson D 2013. The evolution of the Anopheles 16 genomes project. G3 (Bethesda) 3: 1191-1194.

Neves A, Urbinatti PR, Malafronte RS, Fernandes A, Paganini WS, Natal D 2013. Malaria outside the Amazon Region: natural Plasmodium infection in anophelines collected near an indigenous village in the Vale do Rio Branco, Itanhaém, SP, Brazil. Acta Trop 125: 102-106.

Ng TF, Duffy S, Polston JE, Bixby E, Vallad GE, Breitbart M 2011a. Exploring the diversity of plant DNA viruses and their satellites using vector-enabled metagenomics on whiteflies. PLOS ONE 6: e19050.

Ng TF, Willner DL, Lim YW, Schmieder R, Chau B, Nilsson C, Anthony S, Ruan Y, Rohwer F, Breitbart M 2011b. Broad surveys of DNA viral diversity obtained through viral metagenomics of mosquitoes. PLoS ONE 6: e20579.

Ni T, Yue J, Sun G, Zou Y, Wen J, Huang J 2012. Ancient gene transfer from algae to animals: mechanisms and evolutionary significance. BMC Evol Biol 12: 83.

Niare O, Markianos K, Volz J, Oduol F, Toure A, Bagayoko M, Sangare D, Traore SF, Wang R, Blass C 2002. Genetic loci affecting resistance to human malaria parasites in a West African mosquito vector population. Science 298: 213-216.

Nikoh N, Tanaka K, Shibata F, Kondo N, Hizume M, Shimada M, Fukatsu T 2008. Wolbachia genome integrated in an insect chromosome: evolution and fate of laterally transferred endosymbiont genes. Genome Res 18: 272-280.

Noden BH, Pumpuni CB, Vaughan JA, Beier JC 1995. Non-infectious sporozoites in the salivary glands of a minimally susceptible anopheline mosquito. J Parasitol 81: 912-915.

Norris DE, Shurtleff AC, Toure YT, Lanzaro GC 2001. Microsatellite DNA polymorphism and heterozygosity among field and laboratory populations of Anopheles gambiae s.s. (Diptera: Culicidae). J Med Entomol 38: 336-340.

Olayan EMA, Beetsma AL, Butcher GA, Sinden RE, Hurd H 2002. Complete development of mosquito phases of the malaria parasite in vitro. Science 295: 677-679.

Oliveira JH, Gonçalves RL, Oliveira GA, Oliveira PL, Oliveira MF, Barillas-Mury C 2011. Energy metabolism affects susceptibility of Anopheles gambiae mosquitoes to Plasmodium infection. Insect Biochem Mol Biol 41: 349-355.

O'Rourke DH, Raff JA 2010. The human genetic history of the Americas: the final frontier. Curr Biol 20: R202-R207.

Osta MA, Christophides GK, Kafatos FC 2004. Effects of mosquito genes on Plasmodium development. Science 303: 2030-2032.

Ow-Yang CF, Maria FLS 1963. Maintenance of a laboratory colony of Anopheles maculatus Theobald by artificial mating. Mosq News 23: 34-35.

PAHO - Pan-American Health Organization 2011. Report on the situation of malaria in the Americas, 2011. Available from: paho. org $/ \mathrm{hq} /$ index.php?option $=$ com_content $\&$ view $=$ article $\&$ id $=24$ 59:report-on-the-situation-of-malaria-in-the-americas-2008\&Itemid $=2000 \&$ lang $=$ pt.

Pan X, Zhou G, Wu J, Bian G, Lu P, Raikhel AS, Xi Z 2012. Wolbachia induces reactive oxygen species (ROS)-dependent activation of the Toll pathway to control dengue virus in the mosquito Aedes aegypti. Proc Natl Acad Sci USA 109: E23-E31.

Perez AM, Conn J 1992. A polytene chromosome study of four populations of Anopheles aquasalis from Venezuela. Genome 35: 327-331.
Pidiyar VJ, Jangid K, Patole MS, Shouche YS 2004. Studies on cultured and uncultured microbiota of wild Culex quinquefasciatus mosquito midgut based on 16s ribosomal RNA gene analysis. $\mathrm{Am}$ J Trop Med Hyg 70: 597-603.

Pimenta PF, Touray M, Miller L 1994. The journey of malaria sporozoites in the mosquito salivary gland. J Eukaryot Microbiol 41: 608-624.

Pimenta PF, Turco SJ, McConville MJ, Lawyer PG, Perkins PV, Sacks DL 1992. Stage-specific adhesion of Leishmania promastigotes to the sandfly midgut. Science 256 : 1812-1815.

Pinto SB, Lombardo F, Koutsos AC, Waterhouse RM, McKay K, An C, Ramakrishnan C, Kafatos FC, Michel K 2009. Discovery of Plasmodium modulators by genome-wide analysis of circulating hemocytes in Anopheles gambiae. Proc Natl Acad Sci USA 106: 21270-21275.

Povelones M, Waterhouse RM, Kafatos FC, Christophides GK 2009. Leucine-rich repeat protein complex activates mosquito complement in defense against Plasmodium parasites. Science 324: 258-261.

Póvoa M, Wirtz RA, Lacerda RNL, Miles MA, Warhurst D 2001. Malaria vectors in the municipality of Serra do Navio, state of Amapá, Amazon Region, Brazil. Mem Inst Oswaldo Cruz 96: 179-184.

Póvoa MM, Conn JE, Schlichting CD, Amaral JC, Segura MN, da Silva AN, dos Santos CC, Lacerda RN, de Souza RT, Galiza D 2003. Malaria vectors, epidemiology and the re-emergence of Anopheles darlingi in Belém, Pará, Brazil. J Med Entomol 40: 379-386.

Póvoa MM, de Souza RTL, Lacerda RNL, Rosa ES, Galiza D, de Souza JR, Wirtz RA, Schlichting CD, Conn JE 2006. The importance of Anopheles albitarsis $\mathrm{E}$ and An. darlingi in human malaria transmission in Boa Vista, state of Roraima, Brazil. Mem Inst Oswaldo Cruz 101: 163-168.

Pumpuni CB, Beier MS, Nataro JP, Guers LD, Davis JR 1993. Plasmodium falciparum: inhibition of sporogonic development in Anopheles stephensi by Gram-negative bacteria. Exp Parasitol 77: 195-199.

Pumpuni CB, Demaio J, Kent M, Davis JR, Beier JC 1996. Bacterial population dynamics in three anopheline species: the impact on Plasmodium sporogonic development. Am J Trop Med Hyg 54: 214-218.

Ramirez AD, Rocha EM, Krettli AU 1995. Antisporozoite antibodies with protective and nonprotective activities: in vitro and in vivo correlations using Plasmodium gallinaceum, an avian model. $J$ Eukaryot Microbiol 42: 705-708.

Ramirez JL, Garver LS, Brayner FA, Alves LC, Rodrigues J, MolinaCruz A, Barillas-Mury C 2014. The role of hemocytes in Anopheles gambiae antiplasmodial immunity. J Innate Immun 6: 119-128.

Rani A, Sharma A, Rajagopal R, Adak T, Bhatnagar RK 2009. Bacterial diversity analysis of larvae and adult midgut microflora using culture-dependent and culture-independent methods in lab-reared and field-collected Anopheles stephensi - an Asian malarial vector. BMC Microbiol 9: 96.

Ratcliffe NA, Whitten MMA 2004. Vector immunity. In SH Gillespie, GL Smith, A Osbourn (eds.), Microbe-vector interactions in vectorborne disease, Cambridge University Press, Cambridge, p. 199-262.

Reddy BP, Labbe P, Corbel V 2012. Culex genome is not just another genome for comparative genomics. Parasit Vectors 5: 63.

Reyes A, Semenkovich NP, Whiteson K, Rohwer F, Gordon JI 2012. Going viral: next-generation sequencing applied to phage populations in the human gut. Nat Rev Microbiol 10: 607-617.

Rezende HR, Soares RM, Cerutti Jr C, Alves IC, Natal D, Urbinatti PR, Yamasaki T, Falqueto A, Malafronte RS 2009. Entomological characterization and natural infection of anophelines in an area of the Atlantic Forest with autochthonous malaria cases in mountainous region of Espírito Santo state, Brazil. Neotrop Entomol 38: 272-280. 
Ricci I, Damiani C, Capone A, DeFreece C, Rossi P, Favia G 2012. Mosquito/microbiota interactions: from complex relationships to biotechnological perspectives. Curr Opin Microbiol 15: 278-284.

Richman AM, Dimopoulos G, Seeley D, Kafatos FC 1997. Plasmodium activates the innate immune response of Anopheles gambiae mosquitoes. EMBO J 16: 6114-6119.

Riehle MA, Srinivasan P, Moreira CK, Jacobs-Lorena M 2003. Towards genetic manipulation of wild mosquito populations to combat malaria: advances and challenges. J Exp Biol 206: 3809-3816.

Riehle MM, Markianos K, Lambrechts L, Xia A, Sharakhov I, Koella JC, Vernick KD 2007. A major genetic locus controlling natural Plasmodium falciparum infection is shared by East and West African Anopheles gambiae. Malar J 6: 87.

Riehle MM, Markianos K, Niare O, Xu J, Li J, Toure AM, Podiougou B, Oduol F, Diawara S, Diallo M 2006. Natural malaria infection in Anopheles gambiae is regulated by a single genomic control region. Science 312: 577-579.

Riehle MM, Xu J, Lazzaro BP, Rottschaefer SM, Coulibaly B, Sacko M, Niare O, Morlais I, Traore SF, Vernick KD 2008. Anopheles gambiae APL1 is a family of variable LRR proteins required for Rel1-mediated protection from the malaria parasite, Plasmodium berghei. PLoS ONE 3: e3672.

Ríos-Velasquez CM, Martins-Campos KM, Simões RC, Izzo T, dos Santos EV, Pessoa FAC, Lima JBP, Monteiro WM, Secundino NFC, Lacerda MVG, Pimenta PFP 2013. Experimental Plasmodium vivax infection of key Anopheles species from the Brazilian Amazon. Malar J 12: 460.

Rocha EM, Hollingdale MR, Gwadz R, Krettli AU 1993a. Exoerythrocytic development of Plasmodium gallinaceum sporozoites in a chicken fibroblast cell line and inhibition of the cell invasion by specific anti-sporozoite monoclonal antibodies. $J$ Eukaryot Microbiol 40: 64-66.

Rocha EM, Hollingdale MR, Sina B, Leland P, Lopes JD, Krettli AU 1993b. Common epitopes in the circumsporozoite proteins of Plasmodium berghei and Plasmodium gallinaceum identified by monoclonal antibodies to the $P$. gallinaceum circumsporozoite protein. $J$ Eukaryot Microbiol 40: 61-63.

Rodrigues FG, Santos MN, de Carvalho TX, Rocha BC, Riehle MA, Pimenta PF, Abraham EG, Jacobs-Lorena M, de Brito CFA, Moreira LA 2008. Expression of a mutated phospholipase A2 in transgenic Aedes fluviatilis mosquitoes impacts Plasmodium gallinaceum development. Insect Mol Biol 17: 175-183.

Rodrigues J, Brayner FA, Alves LC, Dixit R, Barillas-Mury C 2010. Hemocyte differentiation mediates innate immune memory in Anopheles gambiae mosquitoes. Science 329: 1353-1355.

Rodrigues J, Oliveira GA, Kotsyfakis M, Dixit R, Molina-Cruz A, Jochim R, Barillas-Mury C 2012. An epithelial serine protease, $\mathrm{AgESP}$, is required for Plasmodium invasion in the mosquito Anopheles gambiae. PLoS ONE 7: e35210.

Rohwer F, Prangishvili D, Lindell D 2009. Roles of viruses in the environment. Environ Microbiol 11: 2771-2774.

Rosa-Freitas MG, Lourenço-de-Oliveira R, de Carvalho-Pinto CJ, Flores-Mendoza C, Silva-do-Nascimento TF 1998. Anopheline species complexes in Brazil. Current knowledge of those related to malaria transmission. Mem Inst Oswaldo Cruz 93: 651-655.

Rosario K, Breitbart M 2011. Exploring the viral world through metagenomics. Curr Opin Virol 1: 289-297.

Rosenberg E, Zilber-Rosenberg I 2011. Symbiosis and development: the hologenome concept. Birth Defects Res C Embryo Today 93: 56-66.

Roy SW, Irimia M 2008. Origins of human malaria: rare genomic changes and full mitochondrial genomes confirm the relationship of Plas- modium falciparum to other mammalian parasites, but complicate the origins of Plasmodium vivax. Mol Biol Evol 25: 1192-1198.

Rubio-Palis Y, Wirtz RA, Curtis CF 1992. Malaria entomological inoculation rates in western Venezuela. Acta Trop 52: 167-174.

Sallum MA, Schultz TR, Wilkerson RC 2000. Phylogeny of Anophelinae (Diptera: Culicidae) based on morphological characters. Ann Entomol Soc Am 93: 745-775.

Santos RL, Padilha A, Costa MD, Costa EM, Dantas-Filho HC, Póvoa MM 2009. Malaria vectors in two indigenous reserves of the Brazilian Amazon. Rev Saude Publica 43: 859-868.

Schlein Y, Polacheck I, Yuval B 1985. Mycoses, bacterial infections and antibacterial activity in sandflies (Psychodidae) and their possible role in the transmission of leishmaniasis. Parasitology 90: 57-66.

Schmid-Hempel P, Ebert D 2003. On the evolutionary ecology of specific immune defence. Trends Ecol Evol 18: 27-32.

Scott TW, Takken W, Knols BG, Boete C 2002. The ecology of genetically modified mosquitoes. Science 298: 117-119.

Seed KD, Lazinski DW, Calderwood SB, Camilli A 2013. A bacteriophage encodes its own CRISPR/Cas adaptive response to evade host innate immunity. Nature 494: 489-491.

Serrano-Pinto V, Acosta-Perez M, Luviano-Bazan D, Hurtado-Sil G, Batista CV, Martinez-Barnetche J, Lanz-Mendoza H 2010. Differential expression of proteins in the midgut of Anopheles albimanus infected with Plasmodium berghei. Insect Biochem Mol Biol 40: 752-758.

Shahabuddin M, Pimenta PF 1998. Plasmodium gallinaceum preferentially invades vesicular ATPase-expressing cells in Aedes aegypti midgut. Proc Natl Acad Sci USA 95: 3385-3389.

Sharakhova MV, Hammond MP, Lobo NF, Krzywinski J, Unger MF, Hillenmeyer ME, Bruggner RV, Birney E, Collins FH 2007. Update of the Anopheles gambiae PEST genome assembly. Genome Biol 8: R5.

Siden-Kiamos I, Louis C 2004. Interactions between malaria parasites and their mosquito hosts in the midgut. Insect Biochem Mol Biol 34: 679-685.

Sinden RE 1999. Plasmodium differentiation in the mosquito. Parassitologia 41: 139-148.

Sinden RE, Butcher GA, Beetsma AL 2002. Maintenance of the Plasmodium berghei life cycle. Methods Mol Med 72: 25-40.

Sinden RE, Dawes EJ, Alavi Y, Waldock J, Finney O, Mendoza J, Butcher GA, Andrews L, Hill AV, Gilbert SC 2007. Progression of Plasmodium berghei through Anopheles stephensi is densitydependent. PLoS Pathog 3: e195.

Sinden RE, Matuschewski K 2005. The sporozoite. In IW Sherman (ed.), Molecular approaches to malaria, ASM Press, Washington DC, p. 169-190.

Sinka ME, Bangs MJ, Manguin S, Rubio-Palis Y, Chareonviriyaphap T, Coetzee M, Mbogo CM, Hemingway J, Patil AP, Temperley WH 2012. A global map of dominant malaria vectors. Parasit Vectors 5: 69

Sinka ME, Rubio-Palis Y, Manguin S, Patil AP, Temperley WH, Gething PW, Van Boeckel T, Kabaria CW, Harbach RE, Hay SI 2010. The dominant Anopheles vectors of human malaria in the Americas: occurrence data, distribution maps and bionomic précis. Parasit Vectors 3: 72.

Sinkins SP, Gould F 2006. Gene drive systems for insect disease vectors. Nat Rev Genet 7: 427-435.

Smith RC, Vega-Rodríguez J, Jacobs-Lorena M 2014. The Plasmodium bottleneck: malaria parasite losses in the mosquito vector. Mem Inst Oswaldo Cruz 109: 644-661. 
Solarte Y, Manzano MR, Rocha L, Hurtado H, James MA, ArevaloHerrera M, Herrera S 2011. Plasmodium vivax sporozoite production in Anopheles albimanus mosquitoes for vaccine clinical trials. Am J Trop Med Hyg 84: 28-34.

Somboon P, Prapanthadara LA 2002. Trypsin and aminopeptidase activities in blood-fed females Anopheles dirus (Diptera: Culicidae) of differing susceptibility to Plasmodium yoelii nigeriensis. Southeast Asian J Trop Med Public Health 33: 691-693.

Stern A, Mick E, Tirosh I, Sagy O, Sorek R 2012. CRISPR targeting reveals a reservoir of common phages associated with the human gut microbiome. Genome Res 22: 1985-1994.

Sumitani M, Kasashima K, Yamamoto DS, Yagi K, Yuda M, Matsuoka H, Yoshida S 2013. Reduction of malaria transmission by transgenic mosquitoes expressing an antisporozoite antibody in their salivary glands. Insect Mol Biol 22: 41-51.

Suttle CA 2005. Viruses in the sea. Nature 437: 356-361.

SVS - Secretaria de Vigilância em Saúde 2013 Brasil. Sivep malaria. Dados epidemiológicos de malária, por estado. Brasil 2010 e 2011. Available from: portalsaude.saude.gov.br/portalsaude/arquivos/ pdf/2013/Fev/08/dados malaria brasil_2010 2011 at2013 svs.pdf.

Tabachnick WJ 2003. Reflections on the Anopheles gambiae genome sequence, transgenic mosquitoes and the prospect for controlling malaria and other vector borne diseases. J Med Entomol 40: 597-606.

Tadei WP, Dutary TB 2000. Malaria vectors in the Brazilian Amazon: Anopheles of the subgenus Nyssorhynchus. Rev Inst Med Trop Sao Paulo 42: 87-94.

Takken W, Knols BG 2009. Malaria vector control: current and future strategies. Trends Parasitol 25: 101-104.

Tanenbaum DM, Goll J, Murphy S, Kumar P, Zafar N, Thiagarajan M, Madupu R, Davidsen T, Kagan L, Kravitz S 2010. The JCVI standard operating procedure for annotating prokaryotic metagenomic shotgun sequencing data. Stand Genomic Sci 2: 229-237.

Tason CM, Krettli AU 1978. Aedes fluviatilis (Lutz), a new experimental host for Plasmodium gallinaceum Brumpt. J Parasitol 64: 924-925.

Thomas T, Gilbert J, Meyer F 2012. Metagenomics - a guide from sampling to data analysis. Microb Inform Exp 2: 3 .

Toure YT, Oduola AM, Morel CM 2004. The Anopheles gambiae genome: next steps for malaria vector control. Trends Parasitol 20: $142-149$.

Trager W, Jensen JB 1976. Human malaria parasites in continuous culture. Science 193: 673-675.

Tripet F 2009. Ecological immunology of mosquito-malaria interactions: of non-natural versus natural model systems and their inferences. Parasitology 136: 1935-1942.

Tripet F, Aboagye-Antwi F, Hurd H 2008. Ecological immunology of mosquito-malaria interactions. Trends Parasitol 24: 219-227.

Vaughan JA, Hensley L, Beier JC 1994. Sporogonic development of Plasmodium yoelii in five anopheline species. J Parasitol 80: 674-681.

Vaughan JA, Narum D, Azad AF 1991. Plasmodium berghei ookinete densities in three anopheline species. J Parasitol 77: 758-761.

Vincke IH 1954. Natural history of Plasmodium berghei. Indian $J$ Malariol 8: 245-256.

Vinetz JM, Dave SK, Specht CA, Brameld KA, Xu B, Hayward R, Fidock DA 1999. The chitinase PfCHTl from the human malaria parasite Plasmodium falciparum lacks proenzyme and chitinbinding domains and displays unique substrate preferences. Proc Natl Acad Sci USA 96: 14061-14066.

Vinetz JM, Valenzuela JG, Specht CA, Aravind L, Langer RC, Ribeiro JM, Kaslow DC 2000. Chitinases of the avian malaria parasite
Plasmodium gallinaceum, a class of enzymes necessary for parasite invasion of the mosquito midgut. $J$ Biol Chem 275: 10331-10341.

Volkman SK, Sabeti PC, DeCaprio D, Neafsey DE, Schaffner SF, Milner Jr DA, Daily JP, Sarr O, Ndiaye D, Ndir O, Mboup S, Duraisingh MT, Lukens A, Derr A, Stange-Thomann N, Waggoner S, Onofrio R, Ziaugra L, Mauceli E, Gnerre S, Jaffe DB, Zainoun J, Wiegand RC, Birren BW, Hartl DL, Galagan JE, Lander ES, Wirth DF 2007. A genome-wide map of diversity in Plasmodium falciparum. Nat Genet 39: 113-119.

Volz J, Muller HM, Zdanowicz A, Kafatos FC, Osta MA 2006. A genetic module regulates the melanization response of Anopheles to Plasmodium. Cell Microbiol 8: 1392-1405.

Wang Y, Gilbreath III TM, Kukutla P, Yan G, Xu J 2011. Dynamic gut microbiome across life history of the malaria mosquito Anopheles gambiae in Kenya. PLoS ONE 6: e24767.

Weiss B, Aksoy S 2011. Microbiome influences on insect host vector competence. Trends Parasitol 27: 514-522.

Welburn SC, Maudlin I 1999. Tsetse-trypanosome interactions: rites of passage. Parasitol Today 15: 399-403.

WHO - World Health Organization 2013. WHO Global Malaria Programme. World Malaria Report 2013, WHO, Geneva, 255 pp.

Williamson SJ, Yooseph S 2012. From bacterial to microbial ecosystems (metagenomics). Methods Mol Biol 804: 35-55.

Wolinska J, King KC 2009. Environment can alter selection in hostparasite interactions. Trends Parasitol 25: 236-244.

Wommack KE, Bhavsar J, Ravel J 2008. Metagenomics: read length matters. Appl Environ Microbiol 74: 1453-1463.

Wooley JC, Godzik A, Friedberg I 2010. A primer on metagenomics. PLoS Comput Biol 6: e1000667.

Xu J, Hillyer JF, Coulibaly B, Sacko M, Dao A, Niare O, Riehle MM, Traore SF, Vernick KD 2013. Wild Anopheles funestus mosquito genotypes are permissive for infection with the rodent malaria parasite, Plasmodium berghei. PLoS ONE 8: e61181.

Xu X, Dong Y, Abraham EG, Kocan A, Srinivasan P, Ghosh AK, Sinden RE, Ribeiro JM, Jacobs-Lorena M, Kafatos FC 2005. Transcriptome analysis of Anopheles stephensi-Plasmodium berghei interactions. Mol Biochem Parasitol 142: 76-87.

Yagi H, Nomura T, Nakamura K, Yamazaki S, Kitawaki T, Hori S, Maeda M, Onodera M, Uchiyama T, Fujii S 2004. Crucial role of FOXP3 in the development and function of human CD25 ${ }^{+} \mathrm{CD} 4{ }^{+}$ regulatory T cells. Int Immunol 16: 1643-1656.

Yalcindag E, Elguero E, Arnathau C, Durand P, Akiana J, Anderson TJ, Aubouy A, Balloux F, Besnard P, Bogreau H 2012. Multiple independent introductions of Plasmodium falciparum in South America. Proc Natl Acad Sci USA 109: 511-516.

Yoeli M 1965. Studies on Plasmodium berghei in nature and under experimental conditions. Trans R Soc Trop Med Hyg 59: 255-276.

Yoeli M, Most H, Bone G 1964. Plasmodium berghei: cyclical transmissions by experimentally infected Anopheles quadrimaculatus. Science 144: 1580-1581.

Zdobnov EM, von Mering C, Letunic I, Torrents D, Suyama M, Copley RR, Christophides GK, Thomasova D, Holt RA, Subramanian GM 2002. Comparative genome and proteome analysis of Anopheles gambiae and Drosophila melanogaster. Science 298: 149-159.

Zerpa N, Moreno J, Gonzalez J, Noya O 1998. Colonization and laboratory maintenance of Anopheles albimanus Wiedemann in Venezuela. Rev Inst Med Trop Sao Paulo 40: 173-176.

Zimmerman RH 1992. Ecology of malaria vectors in the Americas and future direction. Mem Inst Oswaldo Cruz 87 (Suppl. III): 371-383. 